Article

\title{
Sustainable Passive Design for Building Performance of Healthy Built Environment in the Lingnan Area
}

\author{
Bin $\mathrm{Li}^{1,2,+}\left(\mathbb{D}\right.$, Weihong Guo ${ }^{1,3,4}$, Xiao Liu ${ }^{1,3,4,5, *,+} \mathbb{1}$, Yuqing Zhang ${ }^{1,4}$, Peter John Russell ${ }^{2,6}$ \\ and Marc Aurel Schnabel ${ }^{7}$ (i) \\ 1 School of Architecture, South China University of Technology, Guangzhou 510641, China; \\ 201810100800@mail.scut.edu.cn (B.L.); whguo@scut.edu.cn (W.G.); 202010100982@mail.scut.edu.cn (Y.Z.) \\ 2 Faculty of Architecture and the Built Environment, Delft University of Technology, \\ 2628 Delft, The Netherlands; p.j.russell@tudelft.nl \\ 3 Architectural Design \& Research Institute Co., Ltd., South China University of Technology, \\ Guangzhou 510641, China \\ 4 State Key Laboratory of Subtropical Building Science, South China University of Technology, \\ Guangzhou 510641, China \\ 5 Department of Urban Planning and Design, Faculty of Architecture, The University of Hong Kong, \\ Hong Kong 999077, China \\ 6 Tsinghua Shenzhen International Graduate School, Tsinghua University, Shenzhen 518055, China \\ 7 Wellington Faculty of Architecture and Design Innovation, Victoria University of Wellington, \\ Wellington 6140, New Zealand; marcaurel.schnabel@vuw.ac.nz \\ * Correspondence: xiaoliu@scut.edu.cn \\ + These authors contributed equally to the study.
}

Citation: Li, B.; Guo, W.; Liu, X.; Zhang, Y.; Russell, P.J.; Schnabel, M.A. Sustainable Passive Design for Building Performance of Healthy Built Environment in the Lingnan Area. Sustainability 2021, 13, 9115. https://doi.org/10.3390/su13169115

Academic Editors: Baojie He, Ayyoob Sharifi and Raffaele Pelorosso

Received: 8 July 2021

Accepted: 12 August 2021

Published: 14 August 2021

Publisher's Note: MDPI stays neutral with regard to jurisdictional claims in published maps and institutional affiliations.

Copyright: (c) 2021 by the authors. Licensee MDPI, Basel, Switzerland. This article is an open access article distributed under the terms and conditions of the Creative Commons Attribution (CC BY) license (https:/ / creativecommons.org/licenses/by/ $4.0 /)$.

\begin{abstract}
Having a healthy built environment becomes increasingly important, especially under the effects of COVID-19. This paper intends to combine sustainable goals based on climate change with passive design principles to achieve a healthy built environment regarding the building performance of residential buildings. The Yuedao Residential Community in the Lingnan area was taken as an example for the research. Based on relevant standards of healthy buildings, the thermal, light, and acoustic environment requirements were determined. The methods of building performance simulation and on-site measurement were used to quantify the research object environments. Then, the outcomes were obtained based on these standards. As observed, the thermal environment's adaptive thermal comfort level was level III. It was hot indoors, but the light and acoustic environments met the requirements. Building designs based on a built environment optimized by external shading systems aim to solve problems through building performance simulation and qualitative analysis. After optimization, the thermal environment improved. According to the literature review, this research focused on a healthy built environment with a sustainable passive design in terms of building performance. A research workflow was established that could be used for more practical research, with abundant research methods. The problems were solved to varying degrees, and the Lingnan architectural culture was preserved. Moreover, this research filled the gap in interactive research on healthy built environments with sustainable passive design regarding building performance.
\end{abstract}

Keywords: sustainability; healthy built environment; passive design; thermal; light; acoustic; residential building; Lingnan area; building performance

\section{Introduction \\ 1.1. Background}

The effects of climate change cause an increasing number of environmental problems, such as urban heat islands, air pollution, bushfire, and flooding [1]. Climate change is caused by energy consumption with carbon emission under anthropogenic activities to some extent [2]. Global energy consumption increased until 2019 [3]. Although COVID-19 has prevented many human activities, energy demand is still increasing in 2021 [4]. The 
energy conservation that has occurred since the Kyoto Protocol was signed has been a global sustainable development issue since 1997 [5]. Therefore, achieving sustainability is essential and critical.

Meanwhile, with the global effects of the COVID-19 phenomenon, people are paying more attention than before to a healthy environment [6]. This is especially true for a healthy built environment, as people spend almost $90 \%$ of their time indoors at present $[7,8]$. With the large amounts of time spent indoors, avoiding massive energy consumption to maintain a healthy environment is a big problem. Therefore, this research focuses on sustainable passive design, aiming to achieve a healthy built environment for the user's health and comfort based on building performance.

\subsection{Literature Review}

To avoid the negative effects of climate change, sustainable goals have been adopted in recent decades [9]. These are guided by the concept of sustainability. Although the definition of sustainability still varies [10], the most cited definition is "development that meets the needs of the present without compromising the ability of future generations to meet their own needs," from the 1987 Brundtland Commission Report [11]. In 1994, the International Council for Building (CIB) defined it as "Creating and operating a healthy built environment based on resource efficiency and ecological design" at the First International Conference on Sustainable Construction [12]. As we can see, the healthy built environment has been combined with the controversial definition of sustainability, but sustainability was initially focused on energy consumption. In 1997, the Kyoto Protocol was issued to promote global energy conservation and emission reductions for sustainable development [13]. In 2002, the World Summit on Sustainable Development held in South Africa promoted the development of sustainability tasks, following the United Nations Stockholm Conference on the Environment in 1972, Rio Earth Summit in 1992, and Millennium Declaration of 2000 [14]. In 2008, the standard ISO 15392:2008 was formulated to identify and establish a general principle for sustainability in building construction. This standard was later revised as ISO 15392:2019 [15]. In recent years, the healthy principle has been merged with sustainability by the UN. In 2015, "Good Health and Well-being" as well as "Sustainable Cities and Communities" were two goals of the Sustainable Development Agenda, adopted by all UN Member States. At present, because of COVID-19, the building of a healthy human settlement for sustainability is emphasized in the UN-Habitat COVID19 Policy and Programme Framework [16]. These show that sustainability has been the global consensus for almost five decades. Alongside the energy consumption problem, the achievement of sustainability goals has been considered urgent since sustainability was first defined. To date, about $40 \%$ of energy consumption in the world has been caused by buildings [17-19]. However, "Buildings don't use energy, people do" [20]. The way a building is used determines the energy waste intensity. Passive building is a good way to save energy for sustainability [21]. Therefore, passive design may be useful in the development of sustainability in a healthy built environment.

The concept of a healthy built environment, based on healthy buildings and related to the Architecture discipline, was initiated in 1981 when the 14th International Union of Architects Conference, held in Warsaw, Poland, published a declaration emphasizing the relationship between Architecture, Man and the Environment in the promotion of people's well-being and health [22]. In 1986, WHO implemented the Healthy Cities Project to drive the substantial development of a healthy living environment. This aimed to create a longterm international development project putting health on the agenda of decision makers in the cities [23]. In 1988, the first Healthy Buildings Conference was held in Stockholm. The 17th Healthy Buildings conference was recently hosted online in Oslo [24]. As well as the developments in academia and in practice, the healthy building concept has been developed in terms of standards and institutions. In 1990, BREEAM, the world standard for assessing, rating, and certifying a building's sustainability was generated by the Building Research Establishment (BRE). To this day, it contains a "Healthy and Well-being" chapter, 
focusing on healthy buildings [25,26]. In 1992, the USA established the National Center for Lead-Safe Housing to solve housing-related health problems. In 1999, the China National Engineering Research Center for Human Settlements (CNERCHS), joining hands with professionals in the areas of Architecture, Physiology, Hygiene, Sociology and Psychology, initiated research into healthy residential buildings [27]. Subsequently, both global and local (China) organizations focused on healthy buildings in multiple areas. In 2004, the first Forum of Theory and Practice on Healthy Housing was held in Beijing, China [28]. In 2006, Professor Hugh Barton from WHO with Marcus Grant published the Health Map, developed from Dahlgren and Whitehead's model in 1991, which explained the circle effect in a healthy environment [29]. In 2014, the International WELL Building Institute published the WELL standard for assessing healthy buildings, based on the LEED standard, which is the first integral healthy building standard in the world [30]. In 2016, the Assessment Standard for Healthy Building (T/ASC02) was published in China to emphasize a healthy environment according to the local situation. The latest version will be published in 2021 [31]. Recently, the WELL Health-Safety Rating was published in 2020 by the Task Force on COVID-19. This helps buildings and organizations to address the health, safety, and well-being of their most valuable asset-people. The healthy built environment concept was developed in the Architecture discipline at least 40 years ago (Figure 1). This began with international organizations, then developed in an increasing number of countries, regarding academic, practice, standard, institutional, or other aspects. China's focus on this is increasing, partly because it started at the end of the 1990s. Moreover, the current effect of COVID-19 is another important reason. With the development of the healthy built environment, the global consensus, especially in academic areas, is more mature than before. How this can be used to solve local healthy built environment problems in a practical way needs further research.

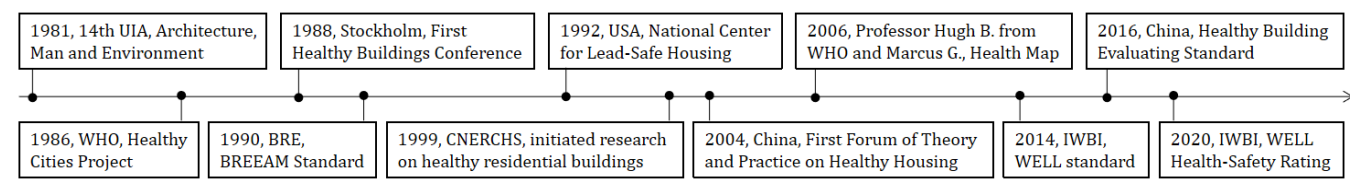

Figure 1. Healthy built environment development timeline.

\subsection{Research Framework}

Based on the literature review of sustainability and the healthy built environment, it is clear that sustainable passive design can be used to achieve a healthy built environment in a practical way. Many researchers have verified that passive building has the strongest effect on a building's energy demands. Passive building designs can reduce energy use [32-34]. This helps avoid climate change for sustainable development, but few scholars have researched the direct relationship between sustainable passive design and the healthy built environment, especially regarding building performance $[35,36]$. Therefore, using sustainable design methods according to the passive building principle to achieve a healthy built environment regarding practical building performance is the focus of our research.

In the built environment, residential buildings accommodate the largest proportion of the 7 billion people in the world [37]. Furthermore, the residential sector is the third highest consumer of energy, following the industrial and transportation sectors [38]. Therefore, this research used the local case study of the Yuedao Residential Community in the Lingnan area to explore the use of sustainable passive design to achieve a healthy built environment from the building performance perspective. The research met the requirements of related healthy building standards. After the building performance simulation and on-site measurement methods, the initial and optimized results will be discussed and conclusions made. The research framework is shown in Figure 2. 


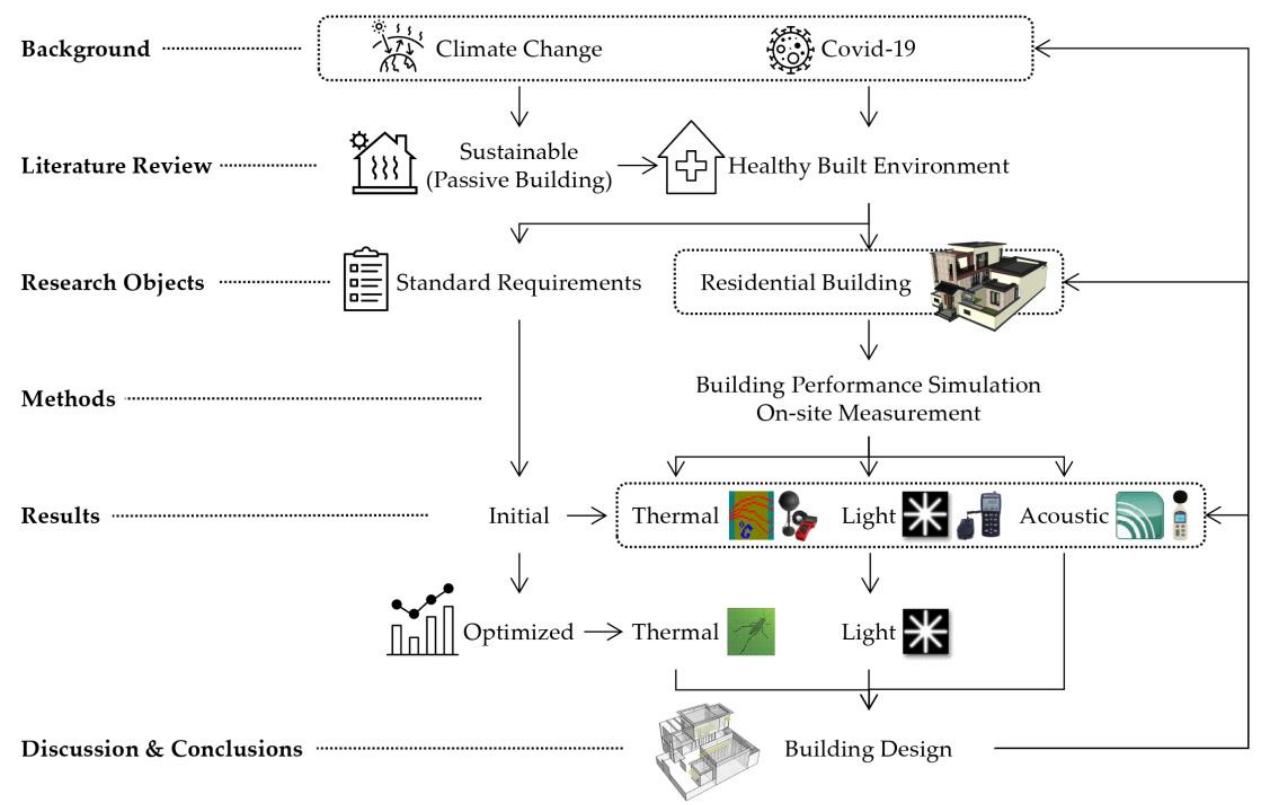

Figure 2. Research framework.

\section{Research Objects}

2.1. Residential Building

The research object is part of the Yuedao Residential Community. The Yuedao Residential Community extends from north to south, with roads dividing it into different residential groups. It can be classified into "neighborhood", "block", and "single courtyard" by scale. However, all the groups are formed with the same single courtyard. It is mirrored in the east-west direction. There are two main kinds of residential buildings with an entrance facing west or east (Figure 3). The single courtyard is $135 \mathrm{~m}^{2}$ in size, with two floors on the north side that include three bedrooms and three bathrooms, and one floor on the south side with one living room, one dining room, one kitchen, and one bathroom. The total site area is $232 \mathrm{~m}^{2}$, with an FAR of 0.58 . All the single courtyards are connected by a high surrounding courtyard wall (Figure 4). This hardly affects the nearby buildings, but each of them forms a microclimate in the courtyard. This is affected by the local meteorological environment.
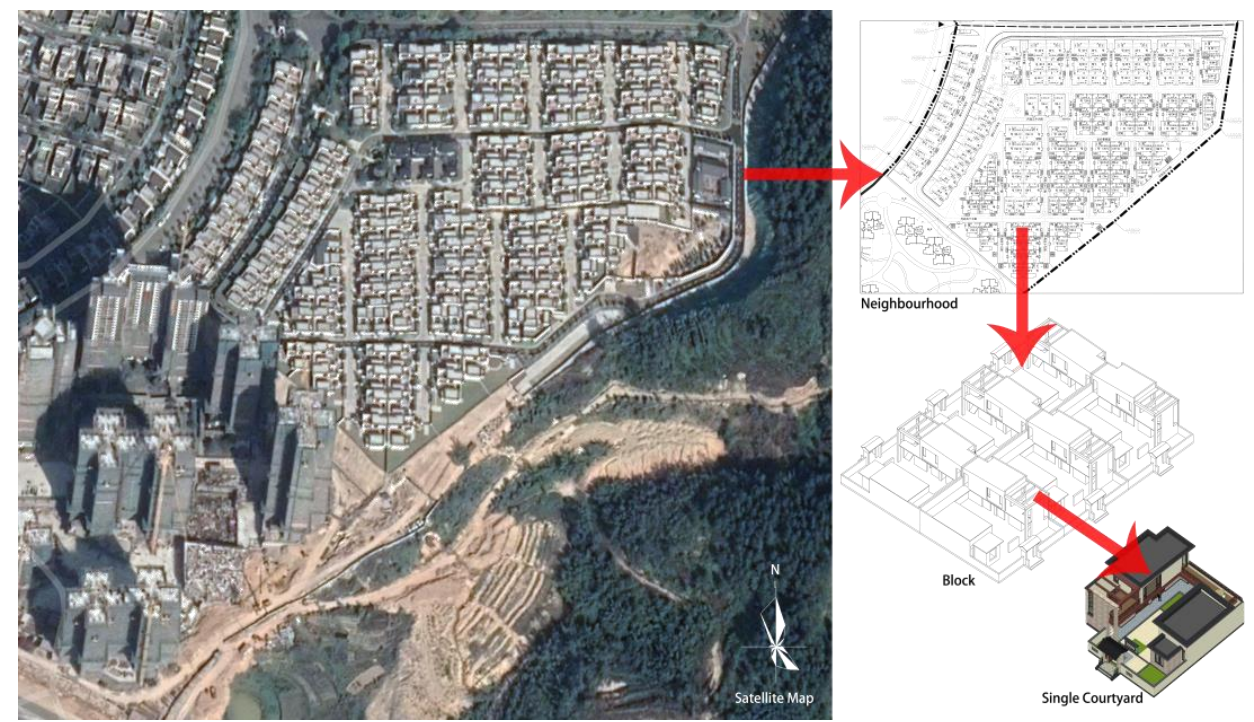

Figure 3. Yuedao Residential Community. 


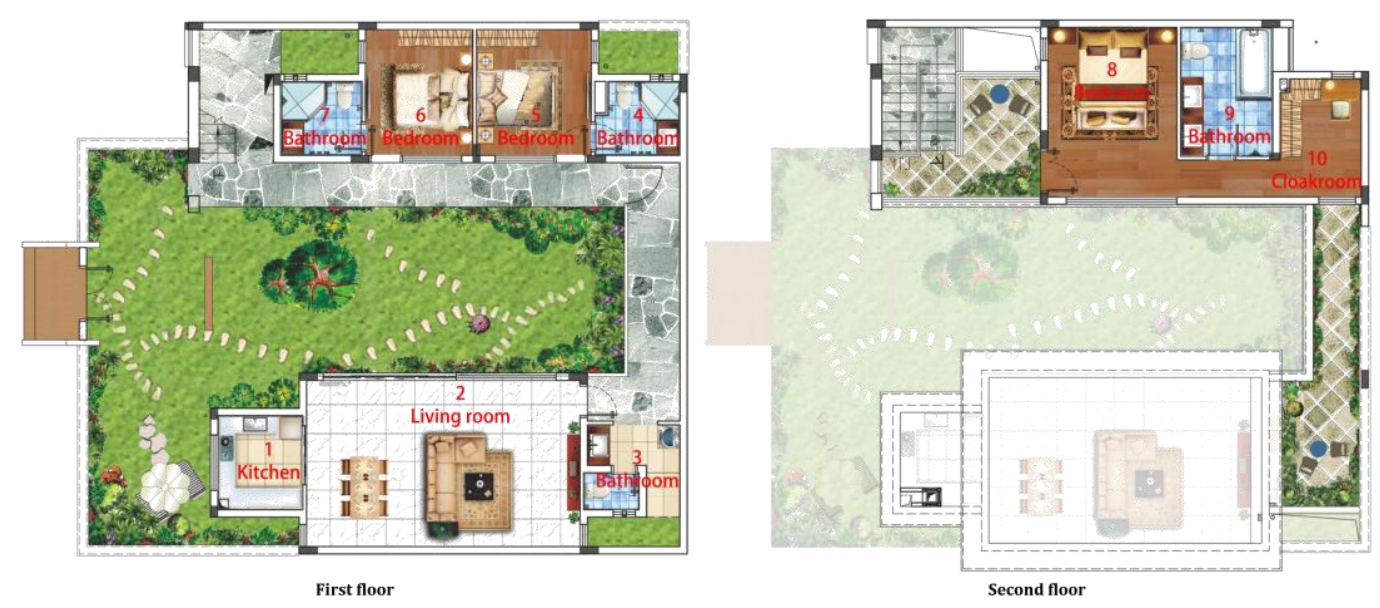

Figure 4. Single courtyard.

The meteorological environment is a hot summer and warm winter, according to the Chinese standard in the Yuedao Residential Community, which is located in Jiangmen city, Lingnan area, south China $[39,40]$. It features a long summer, high temperature, and strong solar radiation. The average temperature in January is higher than $10{ }^{\circ} \mathrm{C}$. The average temperature in July is $25-29^{\circ} \mathrm{C}$. Furthermore, in a year there are from 100 to 200 days with an average daily temperature of $\geq 25^{\circ} \mathrm{C}$. The Lingnan area has a high solar elevation angle and intense solar radiation. Most places in the Lingnan area feature prevailing northeast and east winds from October to March, and southeast and southwest winds from April to September. The annual average wind speed is $1-4 \mathrm{~m} / \mathrm{s}[41,42]$. Hence, the important focuses of this research are thermal, light, and acoustic building performance.

This case study focused on the single courtyard with an entrance facing west. In this situation, the research results contributed at least $50 \%$ to the overall optimization of the Yuedao Residential Community. Sustainable residential building design for a healthy built environment according to passive building principles in the Lingnan area was the ideal way to achieve this without energy use. Therefore, the research used mainly passive building design methods to achieve healthy environments in terms of their thermal, light, and acoustic aspects, according to the related standards of healthy building requirements [43].

\subsection{Standard Requirements}

Healthy environments involve thermal, light, and acoustic aspects. The achievement of a healthy environment in these three aspects, regarding building performance for users, needs to be researched. However, many researchers have been trying to establish standards for designers to reference. These are required in the related standards. The first integral healthy building standard was WELL from the USA, but T/ASC02 in China was used as the reference in this research because of the local environmental effect $[44,45]$.

For healthy thermal environment requirements, T/ASC02 requires that the maximum temperature of the indoor layers of roof and walls does not exceed the exterior annual maximum daily average temperature $\left(t_{e \cdot m a x}\right)$. For indoor thermal environments, it is necessary to reference the Evaluation Standard for Indoor Thermal Environment in Civil Buildings (GB/T 50785) [46]. According to GB/T 50785, the evaluation of an indoor thermal environment should be conducted in the main rooms or a single building. When evaluating a single building, at least $90 \%$ of its main rooms should meet relevant requirements before it can be regarded as reaching the corresponding level. There are three levels in the natural ventilation environment, as shown in Table 1 . The healthy indoor thermal comfort should achieve level I or level II under natural ventilation. The APMV refers to the "adaptive predicted mean vote" generated by optimizing the PMV, which is affected by the local environment [47]. The formula is shown in Equation (1). In fact, GB/T 50785 was generated 
based on ISO 7730 and ASHARE 55. Therefore, the results of the indoor thermal comfort should display the same trend [48].

$$
\mathrm{APMV}=\mathrm{PMV} /(1+\lambda \cdot \mathrm{PMV})
$$

where APMV is adaptive predicted mean vote, PMV is predicted mean vote, and $\lambda$ is the adaptive coefficient. In this research, $\lambda$ is 0.21 according to GB/T 50785 .

Table 1. Evaluation levels of indoor thermal comfort.

\begin{tabular}{cc}
\hline Level & Range \\
\hline I & $-0.5 \leq$ APMV $\leq 0.5$ \\
II & $-1 \leq$ APMV $<-0.5$ or $0.5<$ APMV $\leq 1$ \\
III & APMV $<-1$ or APMV $>1$ \\
\hline
\end{tabular}

For healthy light environment requirements, according to T/ASC02, at least one bedroom should meet the requirement of sunshine time of no less than $3 \mathrm{~h}$, from 8:00 to 16:00 on 20 January in the Lingnan area [49]. The bedroom, living room, and kitchen should directly receive natural daylight. The Standard for Daylighting Design of Buildings (GB 50033) should be followed to ensure that at least one bedroom meets the daylight factor, which is between 2.2 and $7 \%$ in Lingnan area. When there are more than three bedrooms, at least two of them should meet the requirements [50]. For illumination, based on the Standard for Lighting Design of Buildings (GB 50034), the residential building should meet the requirements in Table 2.

Table 2. Standard illumination values for residential buildings.

\begin{tabular}{ccc}
\hline & Room Function & Illumination Value (lx) \\
\hline \multirow{2}{*}{ Living room } & $\begin{array}{c}\text { General activity } \\
\text { Reading and writing }\end{array}$ & 100 \\
& General activity & 300 \\
\hline \multirow{2}{*}{ Bedroom } & Reading and writing & 75 \\
& Dining room & 150 \\
\hline & Bathroom & 150 \\
& & 100 \\
\hline
\end{tabular}

For healthy acoustic environment requirements, the indoor noise level should be lower than $37 \mathrm{~dB}(\mathrm{~A})$ in the bedroom during the night. It is necessary to follow the Environmental Quality Standard for Noise (GB 3096), which states that the indoor noise level of the residential building should be lower than $55 \mathrm{~dB}$ (A) during the day and $45 \mathrm{~dB}$ (A) at night [51].

\section{Methods}

\subsection{Building Performance Simulation}

Building performance simulation is the replication of aspects of the building performance using a computer-based, mathematical model created on the basis of fundamental physical principles and sound engineering practice [52]. This method was used to simulate thermal, light, and acoustic environments to complement on-site measurement. In addition, building performance simulation met relevant standards such as the Standard for Green Performance Calculation of Civil Buildings (JGJ/T 449) and previous research from other scholars [53].

For thermal environmental simulation, the temperatures of the indoor layers of the roof and walls were simulated with Kvalue software to compare them with the $t_{e}$ max. Kvalue is a national certified software developed by the Institute of Building Environment and Energy. It is officially used in the Code for the Thermal Design of Civil Buildings (GB 50176) from 2016. According to GB 50176 and the actual project information, the roof and 
wall parameters were set in the Kvalue software. The built model is shown in Figure 5. Because of the surrounding walls, all used the same structure; the model displayed one of these, and then the results corresponded to the four directions.

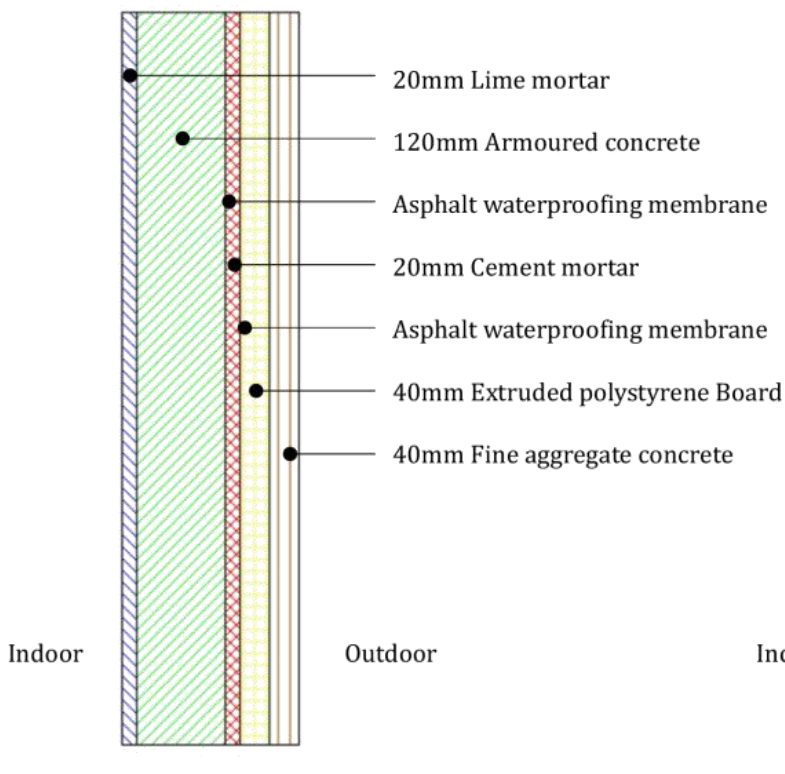

Roof

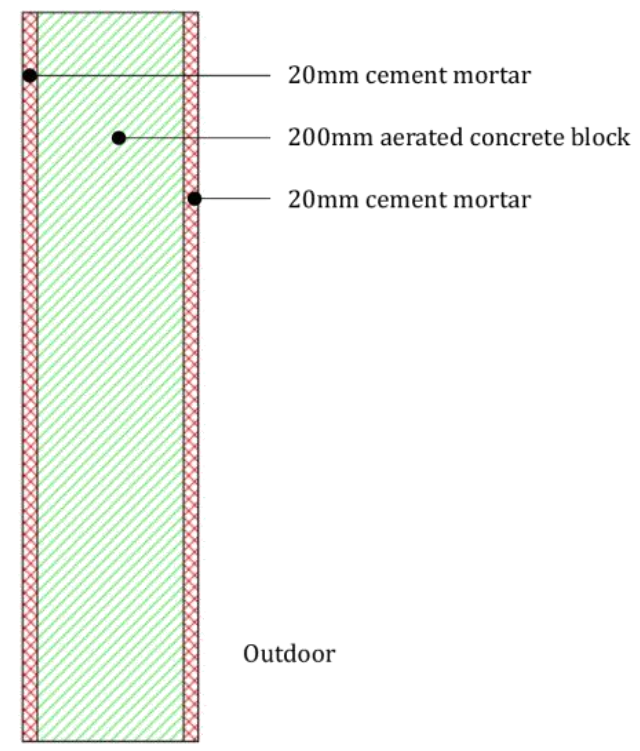

Wall

Figure 5. Structure detail model.

For the light environment simulation, the sunshine time and daylight factor were simulated by Ecotect software based on T/ASC02 and GB 50033 [54-56]. These analyses mainly focused on bedrooms located on the north side of the single courtyard. There were three bedrooms with casement windows. The visible transmittance was 0.639 . The window cleanliness reduction factor was 0.9 . The reflectance of the ceiling, interior wall, and floor were $0.75,0.6$, and 0.4 , respectively. The design illuminance of exterior daylight in Lingnan was $13,500 \mathrm{~lx}$. The daylight climate coefficient was 1.1. All the settings in the software complied with standards and the actual situation (Figure 6).

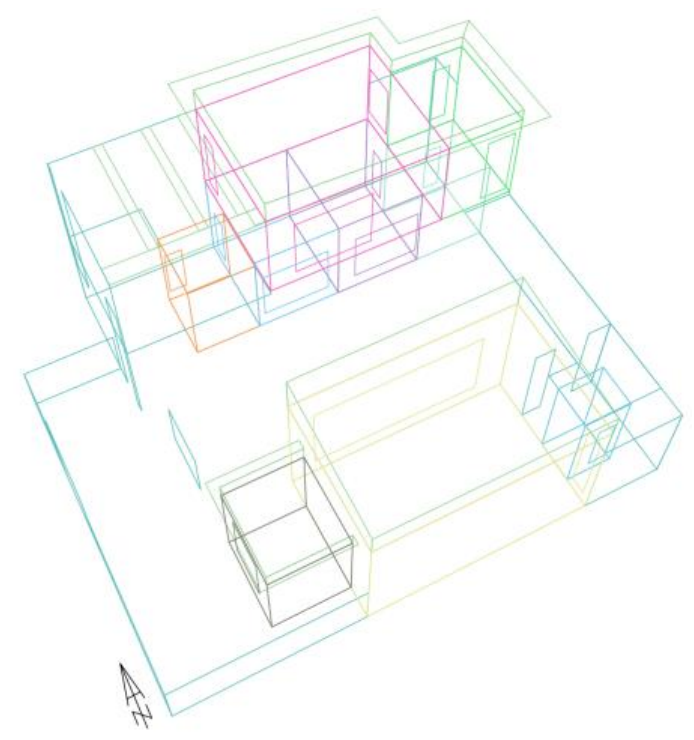

Figure 6. Light simulation model.

For the acoustic environment, considering the effect of a complicated outdoor environment, Cadna/A was used to simulate the outdoor noise level [57]. Cadna/A is the 
simulation software from DataKustik $\mathrm{GmbH}$ for the calculation, presentation, assessment, and prediction of environmental noise, which was certified by ISO 9001:2015 [58]. The simulation model, according to the neighborhood situation, was built in the software in line with the traffic, terrain, and buildings (Figure 7).

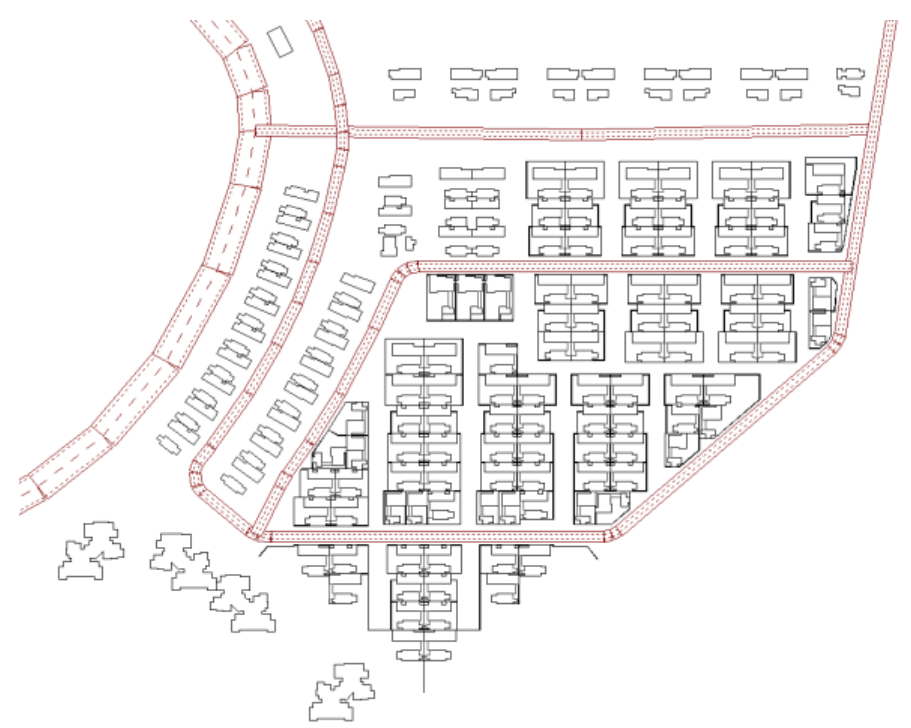

Figure 7. Acoustic simulation model.

\subsection{On-Site Measurement}

The on-site measurement method was also used in this research to develop comprehensive results [59]. The data were collected by the related instruments [60]. For the thermal environment, the BX portable weather station was used to collect the outdoor air velocity $(\mathrm{V})$, wind direction, atmospheric pressure $(\mathrm{atm})$, air temperature $\left(\mathrm{t}_{\text {out }}\right)$, and humidity $\left(\mathrm{RH}_{\text {out }}\right)$ data. At the same time, the data were collected using TES-1341 anemometers and JTR04 black-bulb thermometers in 10 rooms to record indoor air temperature $\left(t_{\text {in }}\right)$, humidity $\left(\mathrm{RH}_{\text {in }}\right)$, air velocity $\left(\mathrm{V}_{\mathrm{a}}\right)$, and 24 -h black globe temperature $\left(\mathrm{t}_{\mathrm{g}}\right)$, starting at 1:30 a.m. on 18 July 2019 (Figure 8). Based on the Standard of Test Methods for Thermal Environment of Buildings [61], the data of $\mathrm{RH}_{\mathrm{in}}$ and $\mathrm{t}_{\mathrm{g}}$ were collected $0.6 \mathrm{~m}$ above the ground, while the data of $t_{\text {in }}$ and $V_{a}$ were collected $1.1 \mathrm{~m}$ above the ground (Figure 8 and Table 3).

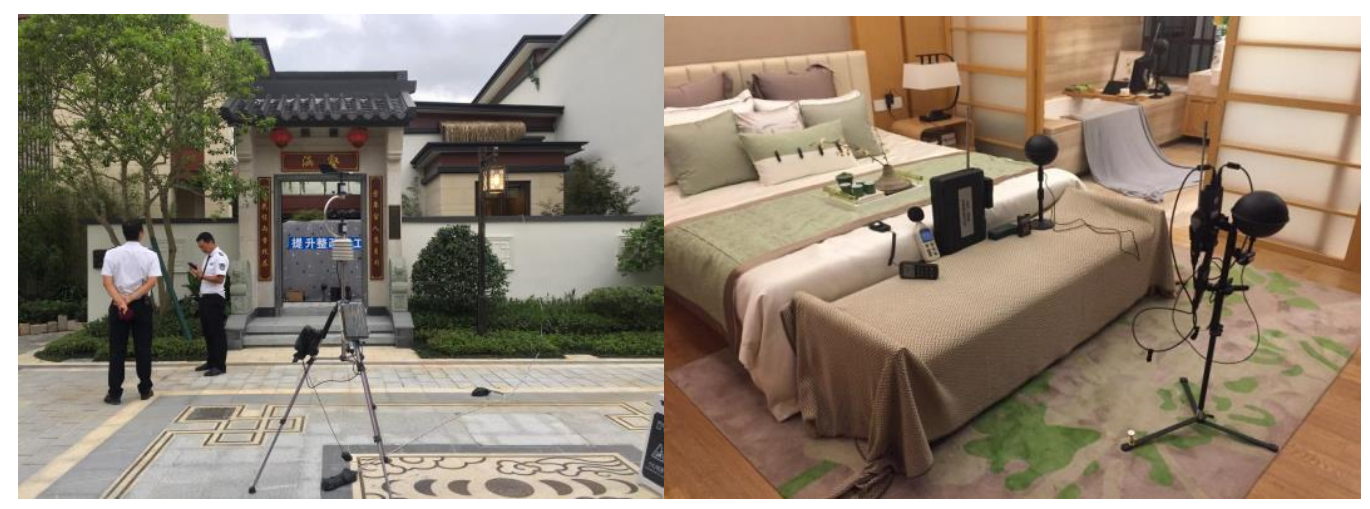

Figure 8. On-site measurement. 
Table 3. Thermal environment instruments and parameters.

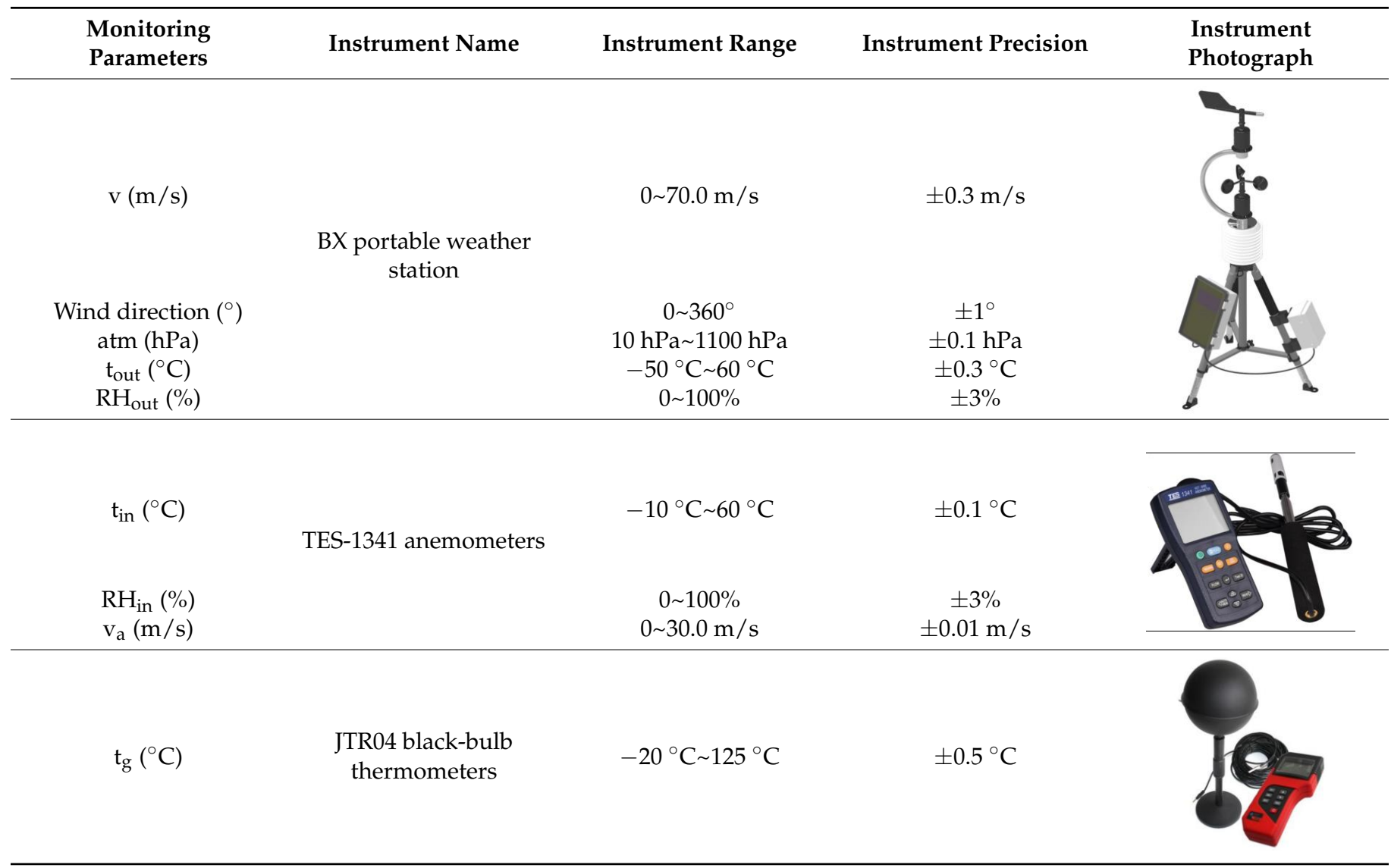

For the light environment, on-site measurement focused on illumination during the night and was conducted with the TES-1339R illuminometer (Table 4). The illuminance was detected according to GB 50034 and Measurement Methods for Lighting (GB $\backslash \mathrm{T}$ 5700) $[62,63]$. The detection time ranged from 7:00 p.m. to 12:00 p.m. on 18 July 2019 . The measurement height was $0.75 \mathrm{~m}$ above the ground. The detected positions were located in No.1 Kitchen, No. 3 Bathroom, No. 6 Bedroom, and No. 10 Cloakroom.

Table 4. Light environment instruments and parameters.

\begin{tabular}{cc} 
Instrument range & $99.99-999,900 \mathrm{Lx} / 9.999-99,990$ \\
& $\mathrm{FC}_{\mathrm{C}}$ \\
& \\
Instrument precision & $\pm 3 \%$ \\
Resolution ratio & $0.01 \mathrm{Lx}, 0.001 \mathrm{FC}$ \\
Measuring speed & $5 \mathrm{times} / \mathrm{s}$ \\
\hline
\end{tabular}

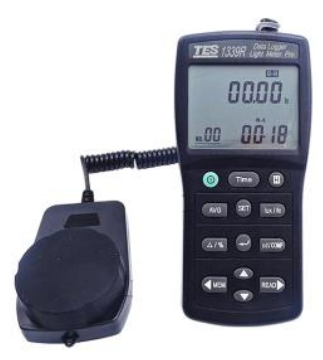

For the acoustic environment, the indoor noise level was detected by the GM1356 noise meter according to GB 3096 (Table 5). In this standard, daytime refers to the time period from 6:00 a.m. to 10:00 p.m., and the nighttime period is from 10:00 p.m. to 6:00 a.m. Because most users go to work during the daytime, under the limitation of the detection situation, the on-site measurement started at 6:00 p.m. on 18 July 2019 and ended at 6:00 a.m. on 19 July 2019. The measurement positions were $1 \mathrm{~m}$ away from the wall and window in case of reflecting effects. The measurement height was $1.5 \mathrm{~m}$ above the ground, 
according to the GB 3096. No. 2 Living room, No. 5 Bedroom, No. 6 Bedroom, and No. 8 Bedroom were detected indoors.

Table 5. Acoustic environment instruments and parameters.

$\begin{array}{ccc}\text { Instrument range } & \pm 1.5 \mathrm{~dB} \\ \text { nstrument precision } & 31.5 \mathrm{~Hz} 8.5 \mathrm{KHz} \\ \text { Resolution ratio } & 2 \mathrm{times} / \mathrm{s} \\ \text { Measuring speed } & \end{array}$

\section{Results}

\subsection{Initial Results}

After the building performance simulation and on-site measurement, the initial results were worked out. For the thermal environment, Kvalue software simulated $t_{e} \cdot \max$, the maximum temperature of the indoor layers of the roof and walls. The $t_{e} \max$ was $37^{\circ} \mathrm{C}$, the maximum indoor temperatures of the roof, east wall, west wall, north wall, and south wall were $34.99,35.30,35.35,35.08$, and $35.23{ }^{\circ} \mathrm{C}$, respectively. The maximum indoor temperature of roof and walls was lower than the $t_{e} \max$, which met the requirements. The roof simulation results in Kvalue are shown in Figure 9. From the on-site measurement, the temperature data of outdoor and indoor were recorded. The BX portable weather station recorded a daily mean outdoor temperature of $32.61{ }^{\circ} \mathrm{C}$. The indoor temperature of the No.1 kitchen was higher than the outdoor temperature during 14:30-16:00 (Figure 10). That was because the kitchen window faced west. China is located in the northern hemisphere, so the sunshine from the west fell directly indoors in the afternoon. This proved that the maximum temperature of the indoor wall layers could be found on the west wall. The indoor data were collected from nine rooms to evaluate the adaptive thermal comfort. The No. 4 Bathroom data were not recorded successfully. However, this still met the requirements of GB/T 50785, which requires evaluating at least $90 \%$ of the rooms. The result showed that the thermal comfort level of the measurement room was level III, whether for the single room or the whole building, which meant that the room was hot in summer under natural ventilation (Figure 11). Therefore, the hot indoors problem should be optimized.

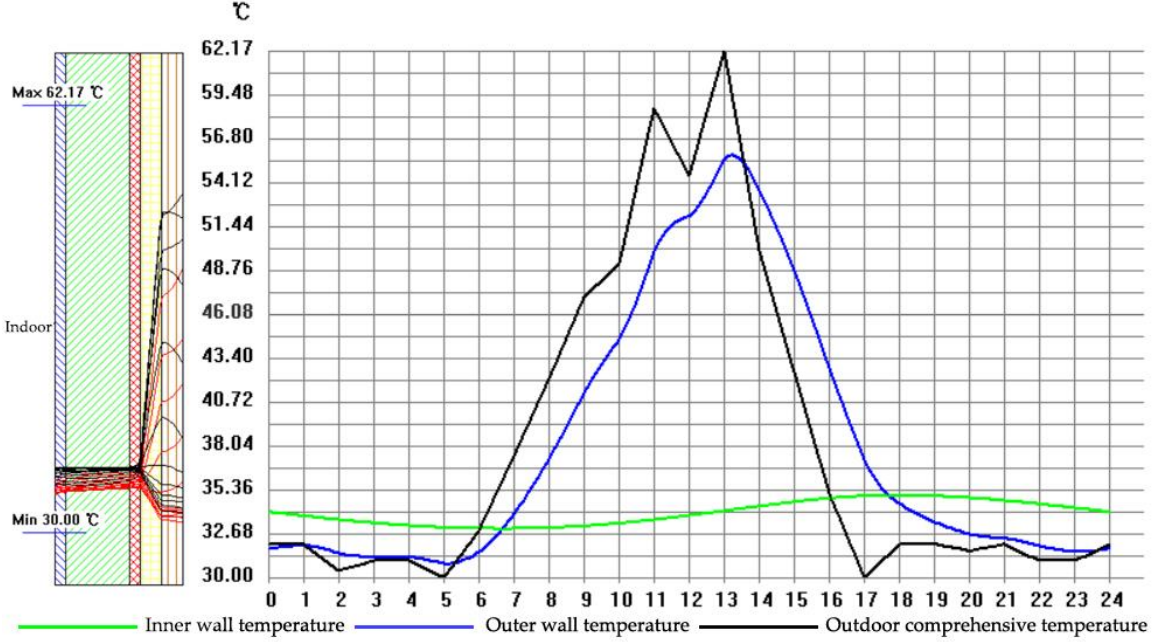

Figure 9. Roof simulation result by Kvalue. 


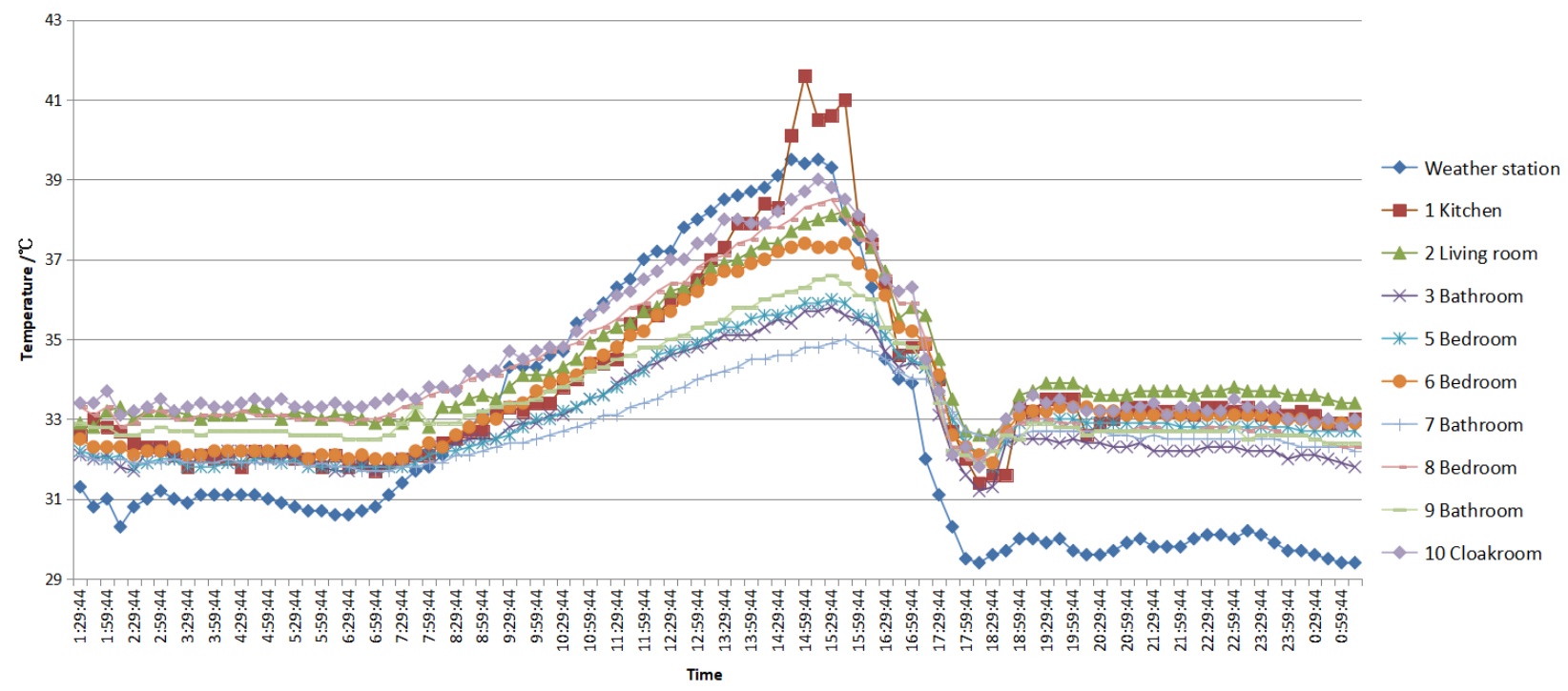

Figure 10. Outdoor and indoor temperature.

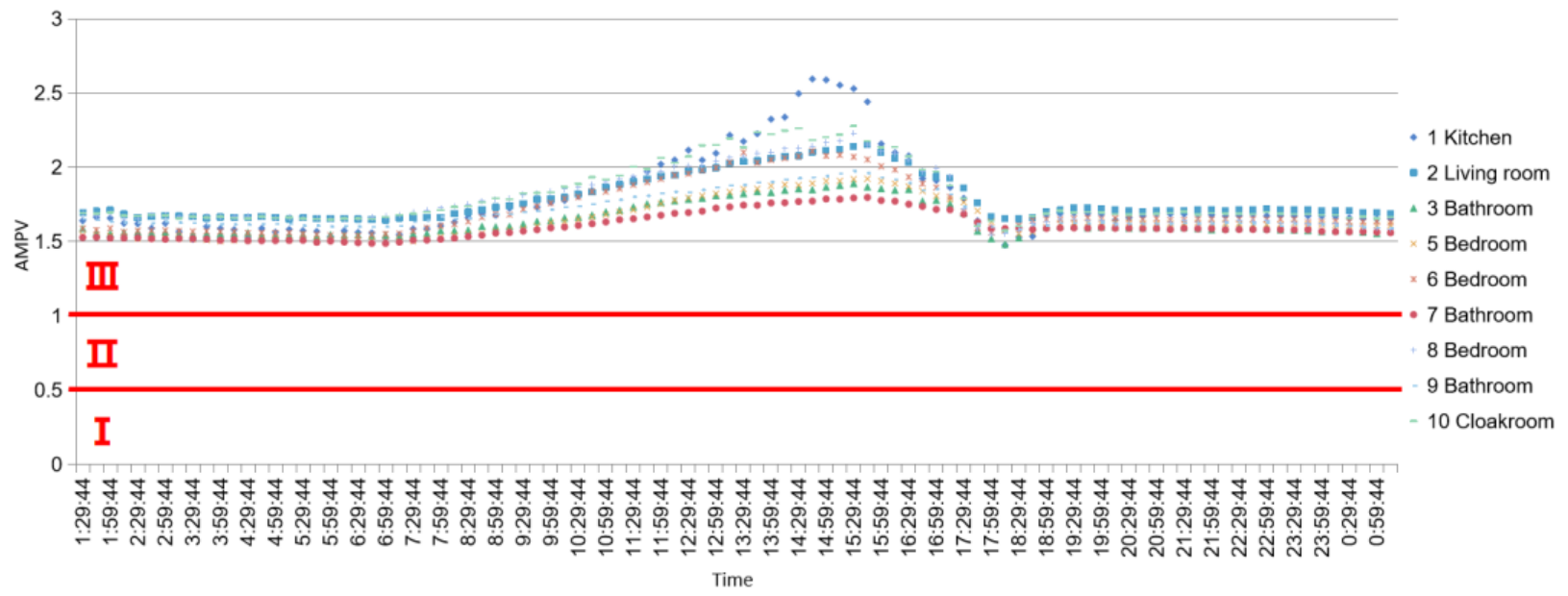

Figure 11. Thermal level results.

For the light environment, the sunshine time for the three bedrooms was at least $4.04 \mathrm{~h}$ according to the Ecotect simulation. This was especially true for the No. 8 Bedroom on the second floor; the window faces south, so the room receives constant sunshine. The sunshine time met the requirement of no less than $3 \mathrm{~h}$ from 8:00 to 16:00 on 20 January (Figure 12). Additionally, the bedroom, living room and kitchen with the windows directly obtained natural daylight. Therefore, this also met the requirements of T/ASC02. Regarding the daylight factor, the single courtyard simulation results are shown in Figure 13. The average value of No. 5 and 6 Bedrooms was $6.14 \%$ on the first floor. The average value of the No. 8 Bedroom was $5.9 \%$ on the second floor. They all fell within the range between 2.2 and $7 \%$, according to GB 50033. Moreover, for illumination purposes, the stable illumination values of No. 1 Kitchen, No. 3 Bathroom, No. 6 Bedroom, and No. 10 Cloakroom were 105, 195, 140, and $75 \mathrm{~lx}$, respectively (Figure 14). They all met the requirements, and no optimization was needed. 

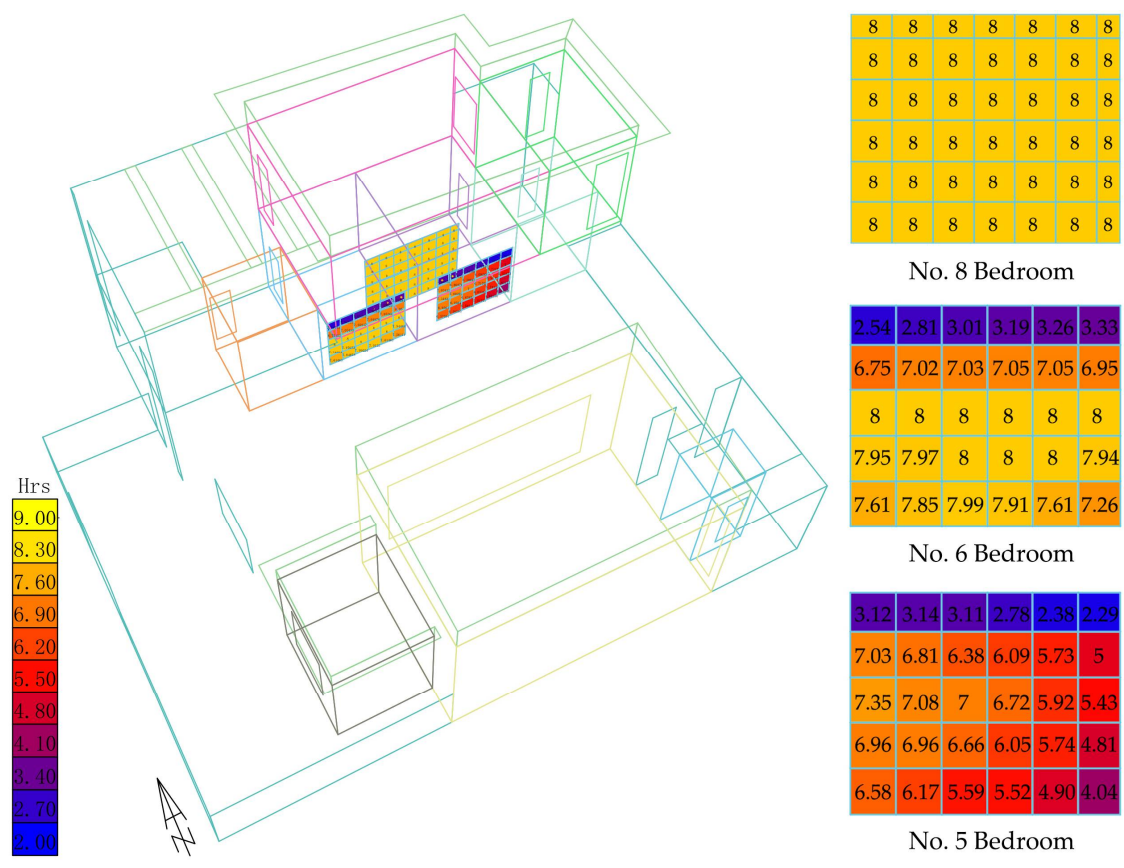

No. 8 Bedroom

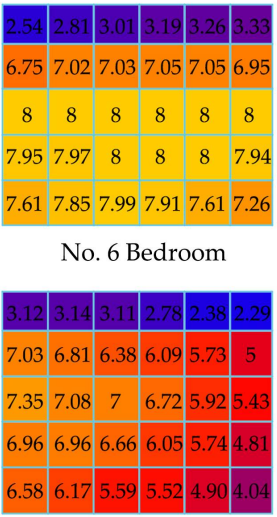

No. 5 Bedroom

Figure 12. Sunshine time simulation results.
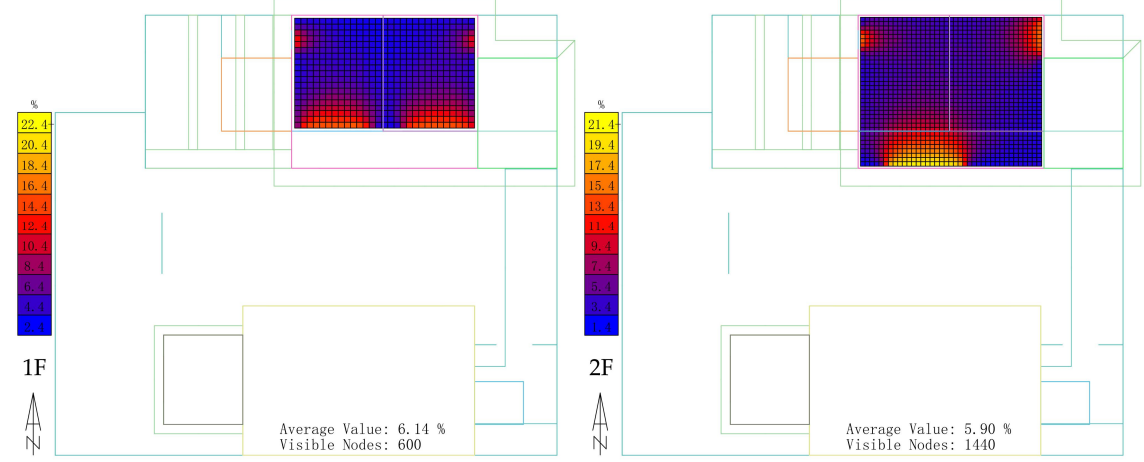

Figure 13. Daylight factor simulation results.
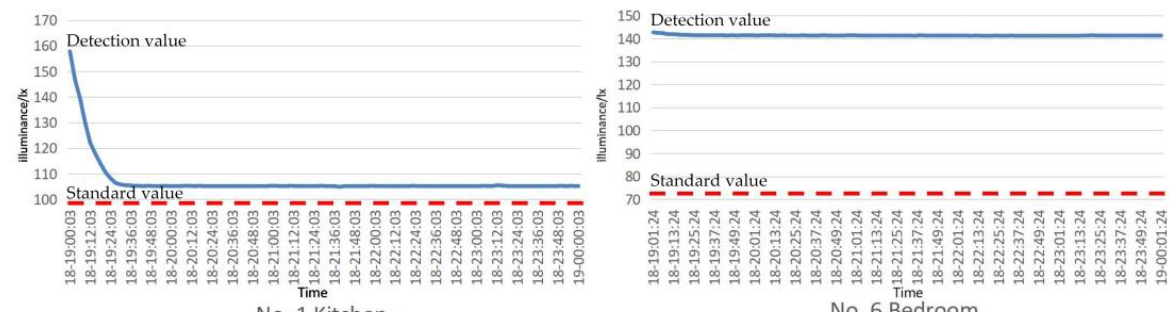

No. 1 Kitchen

No. 6 Bedroom
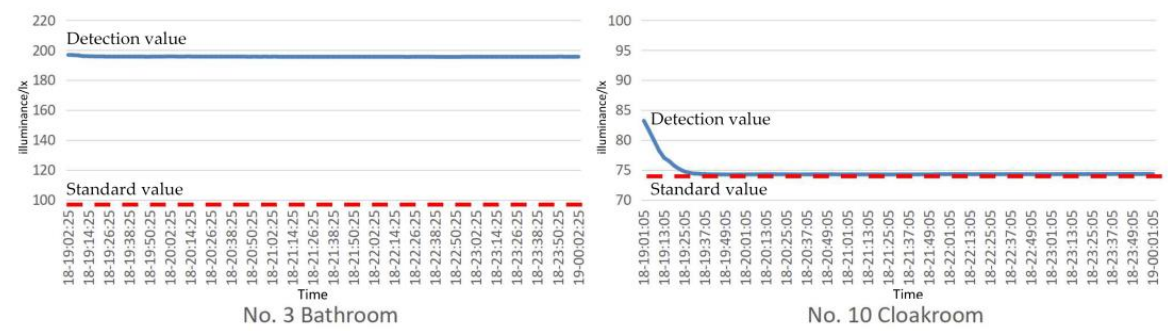

Figure 14. Detection illuminance value. 
For the acoustic environment, Cadna/A software was used to simulate the outdoor acoustic environment. The initial simulation results of the neighborhood noise level during the day and night are shown in Figure 15. The outdoor noise level was 21-55 db (A) during the day, and 11-45 db (A) at night. They all met the standard requirements. In the on-site measurement, the indoor noise level was monitored during the day and night. Most detection values did not exceed $37 \mathrm{db}(\mathrm{A})$, whether during the day or night, and the noise levels of all detected positions met the requirements (Figure 16). It was evident that the acoustic environment of the Yuedao Residential Community contributed to a healthy environment and sustainability.
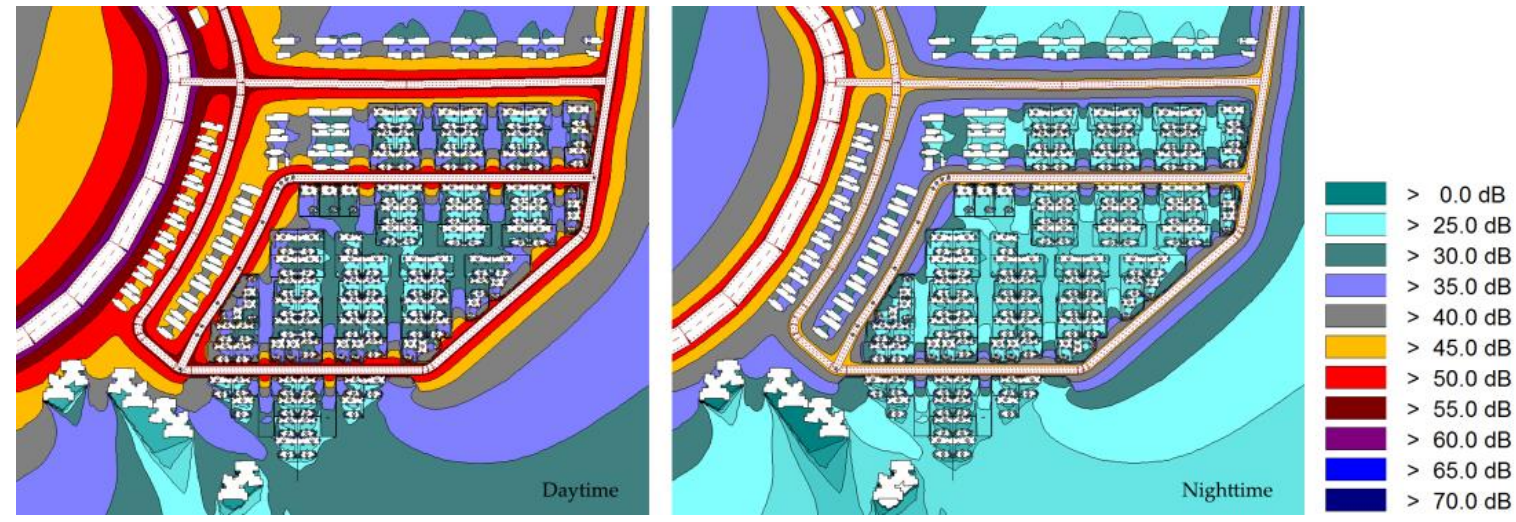

Figure 15. Acoustic simulation results by Cadna/A.

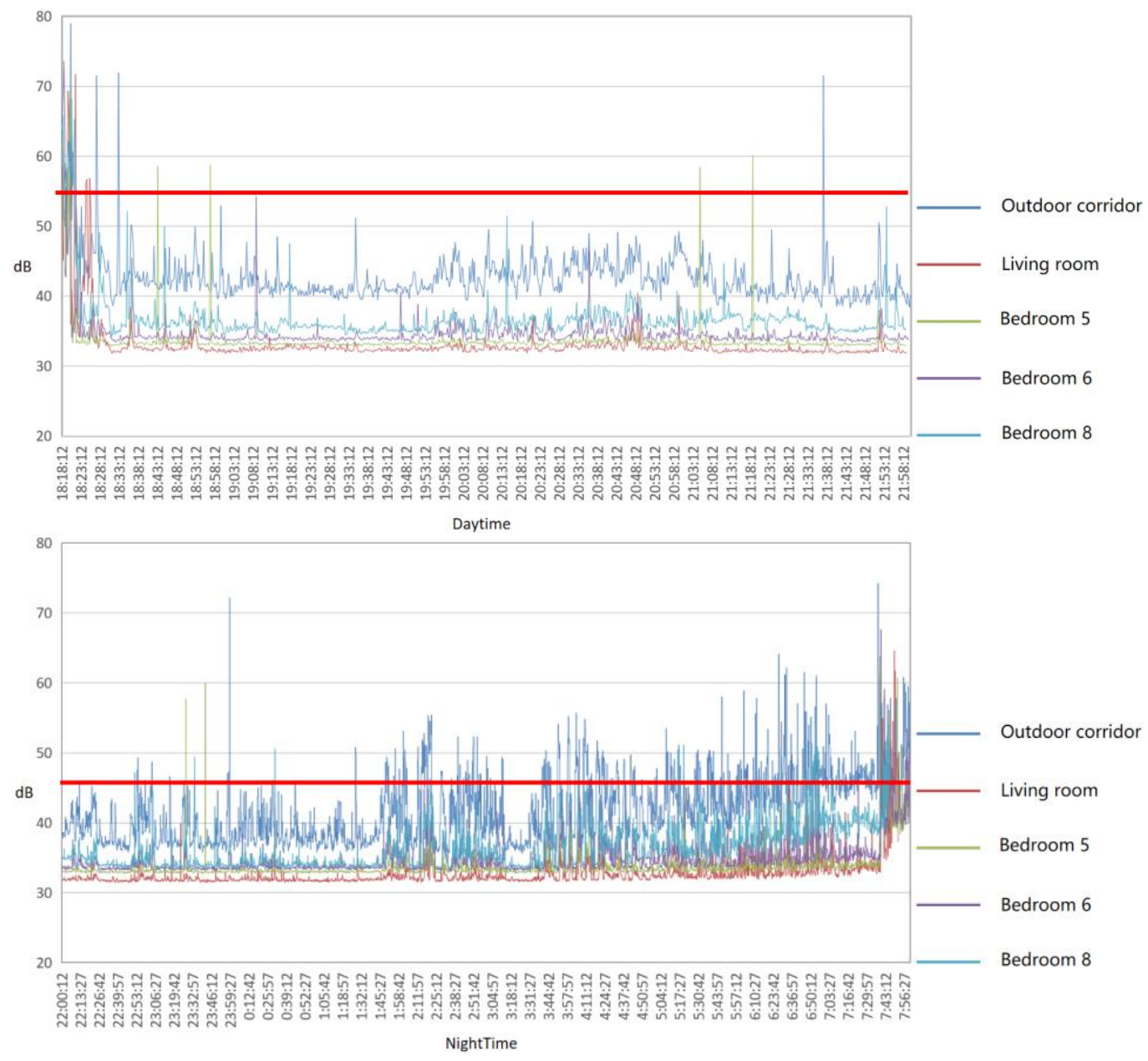

Figure 16. Acoustic on-site measurement results. 


\subsection{Optimized Results}

According to building performance simulations and on-site measurements of thermal, light, and acoustic environments in a single courtyard (facing west) in Lingnan, the indoor thermal environment failed to meet the required levels I or II under natural ventilation, but the light and acoustic environment were good. The problem of the hot indoor environment should be solved. However, the on-site measurement of an indoor thermal environment needed to be carried out in a built project, and it was impossible to build a real optimized project at the time. Thus, a building performance simulation was used to solve this problem.

According to the thermal environment requirements, it was first necessary to ensure that the structural details of the roof and walls allowed a maximum temperature of indoor layers lower than $t_{e} \max$. This was proved above. Therefore, the optimized building design needed to focus on the external walls, according to the passive building principle [64]. Combining this with the field survey, as shown in Figure 17, the building's shading was not enough. Based on local Lingnan building culture, residential buildings are always shaded by eaves. Figure 18 shows an example of a Lingnan building with sunshades. Therefore, the optimization strategies, combined with sunshades, attempted to solve these problems and reflect the local architectural characteristics. Moreover, many scholars have proved that the sunshades are a useful way to achieve energy savings. They help to achieve sustainability $[65,66]$. Therefore, the optimization design aimed to form external shading.

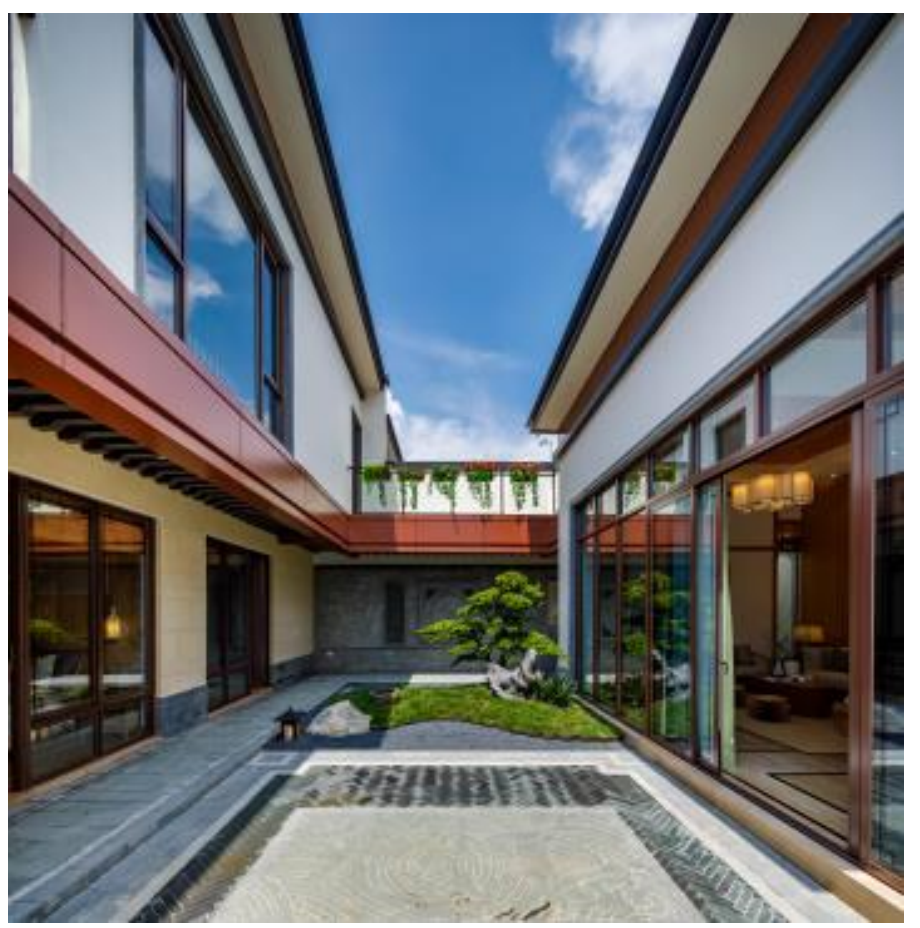

Figure 17. Inside courtyard. 


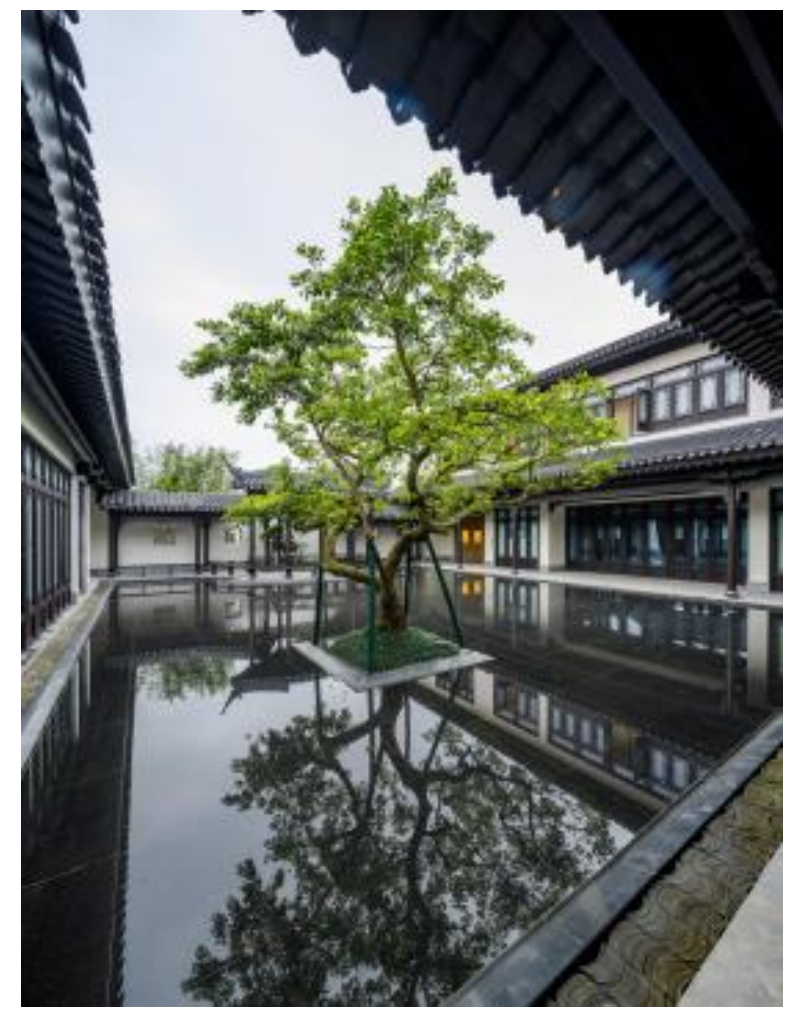

Figure 18. Sunshade.

The initial results showed that the single courtyard was hot indoors. The No. 1 Kitchen had a west-facing window, which needed to be optimized first. Considering the function of the main rooms such as the No. 2 Living room for receiving the public, the No. 8 and 9 Bedrooms with a private bathroom and the No. 10 Cloakroom were too hot, after the hottest room, the No. 1 Kitchen. The optimization model added sunshades to the windows of these rooms, shown in Figure 19.

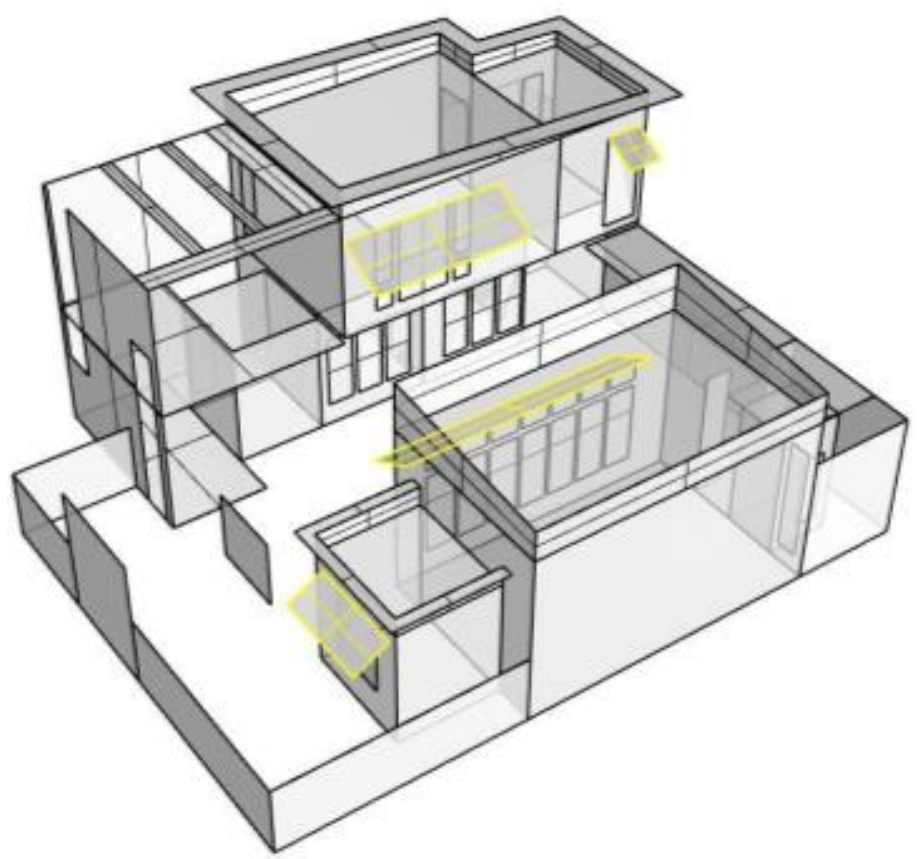

Figure 19. Optimized model. 
The building performance simulation was based on Rhinoceros software with Ladybug and Honeybee plugins. Ladybug imports standard EnergyPlus Weather files (.epw) into Grasshopper. Honeybee is an extension of Ladybug that increases its ability to work with EnergyPlus to calculate the adaptive thermal comfort [67]. The simulation condition was natural ventilation. After completing the workflow and setting up all the parameters, the calculation was started (Figure 20).

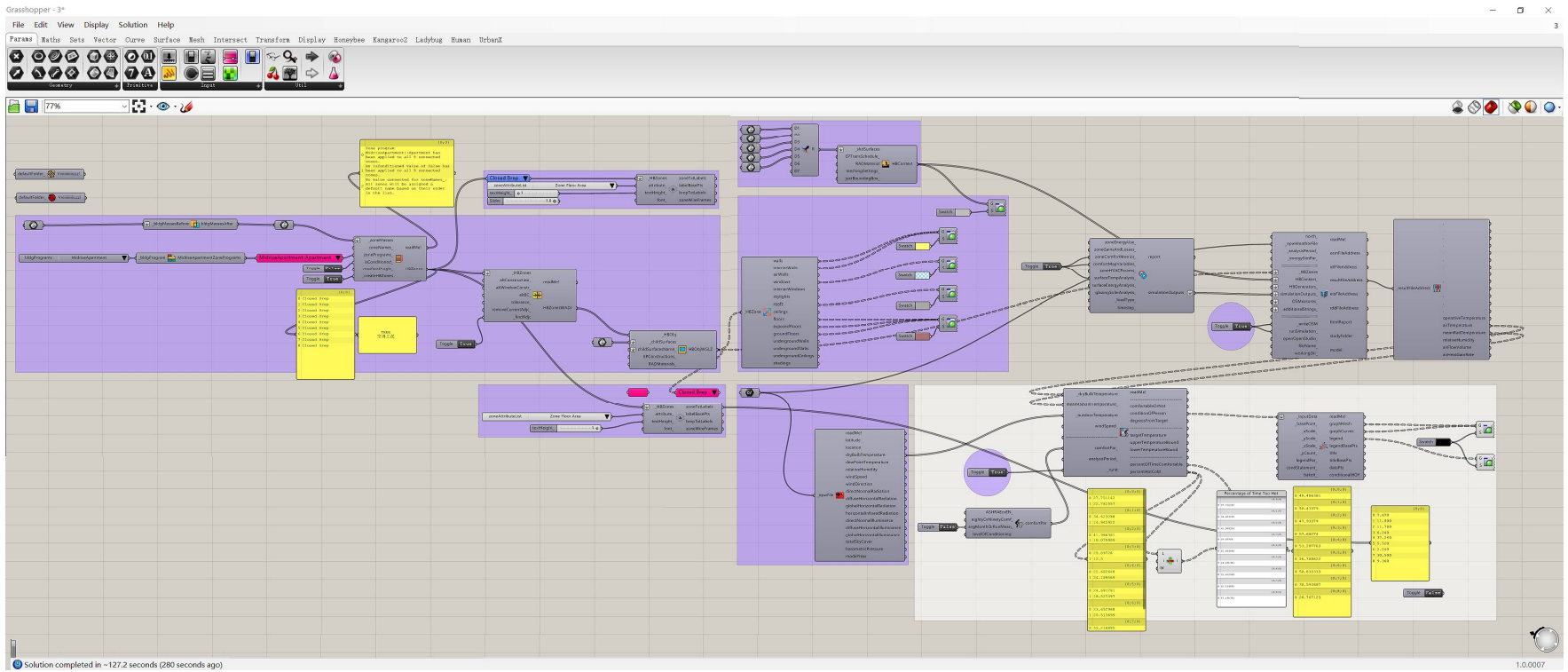

Figure 20. Simulation workflow.

After simulating the initial and optimization building design, the results showed that each room's indoor heat problem was solved to varying degrees. Comparison simulation initial and optimization results are shown in Figure 21. The most optimized indoor thermal environment was $25.78 \%$ in the No. 8 and 9 Bedrooms with bathroom. Furthermore, the heat problems of the No. 1 Kitchen and No. 10 Cloakroom were solved by 17.57 and $20.80 \%$, respectively. The No. 2 Living room faced north, with big windows, so it was not optimized much $(9.76 \%)$. However, all the indoor thermal environments were better than before, using only the passive design of sunshades.

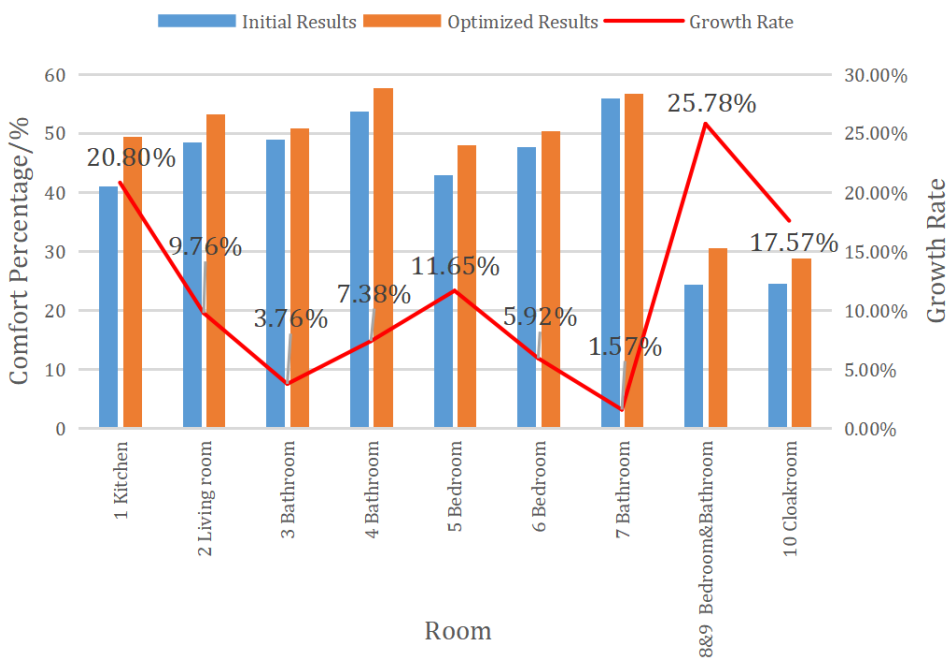

Figure 21. Compared simulation results.

However, the light environment will be directly affected by the sunshades. Even though the initial light environment was good, the optimized light environment needed to 
be confirmed. Therefore, Ecotect software was used for building performance simulation based on optimized building design. The sunshine time and daylight factor were simulated separately (Figures 22 and 23). The sunshine time was especially changed in the No. 8 Bedroom. The value of the No. 5 Bedroom was not changed, as the sunshades were added only on the second floor. Furthermore, the value of the No. 6 Bedroom changed only a little. The optimized sunshine time results met the T/ASC02 requirements. The daylight factor was $6.07 \%$ on the first floor and $4.02 \%$ on the second floor. It decreased a but still ranged between 2.2 and 7\% according to GB 50033. Therefore, the light environments all met the requirements offering a healthy environment and sustainability to users of passive design.

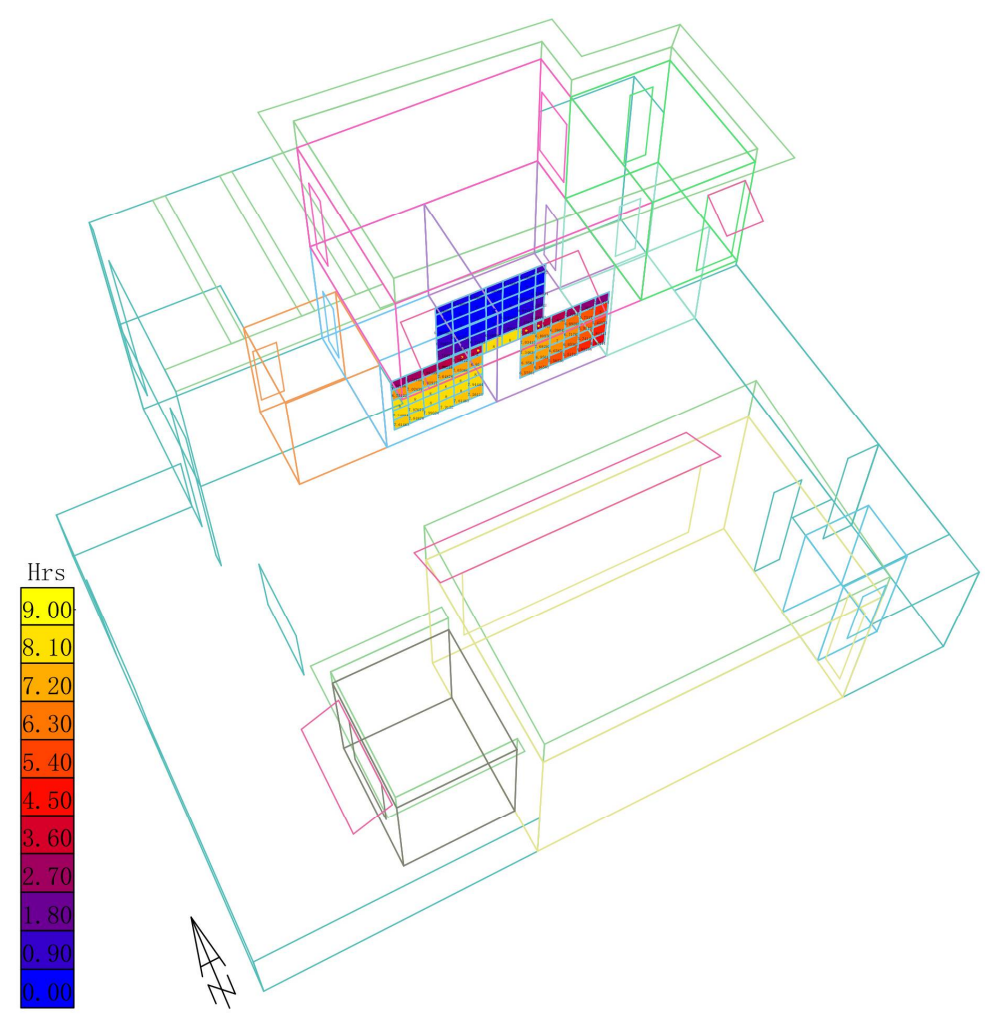

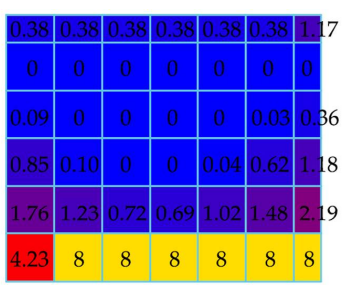

No. 8 Bedroom

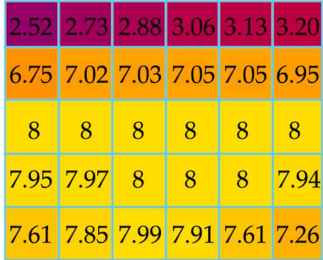

No. 6 Bedroom

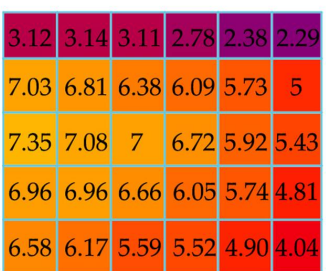

No. 5 Bedroom

Figure 22. Optimized sunshine time simulation results.
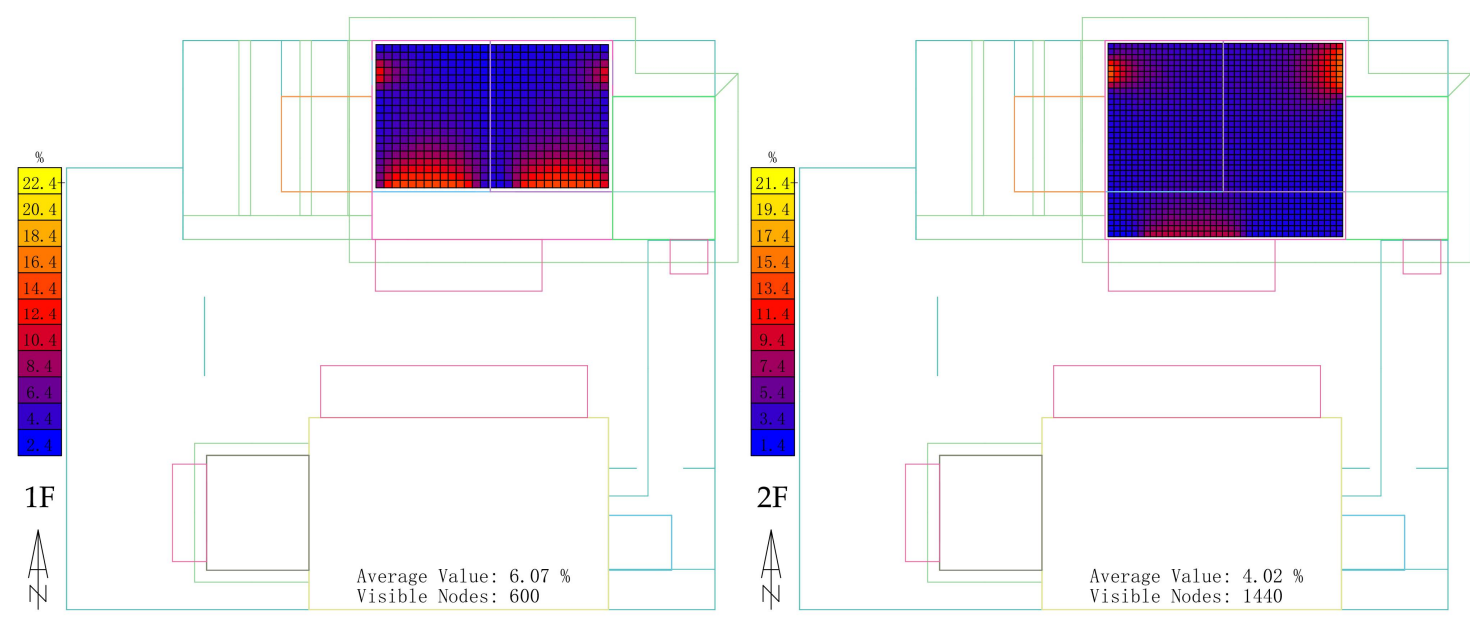

Figure 23. Optimized daylight factor simulation results. 


\section{Discussion}

\subsection{Comparisons}

In this paper, the single courtyard (facing west) of the Yuedao Residential Community was used to research how to achieve a healthy built environment using sustainable passive design. In view of the Lingnan environmental characteristics and related standards, building performance simulation and on-site measurement methods were used for thermal, light, and acoustic environments. The initial results showed that the thermal environment could not meet levels I and II under natural ventilation. It was hot indoors, although the maximum temperature of the indoor layers was lower than $t_{e} \max$, according to the requirements. For the light environment, the sunshine time and daylight factor all met the requirements, according to the simulation. The illumination condition in the rooms detected with on-site measurement also reached the standards. The acoustic environment satisfied both the outdoor and indoor requirements. Given this, the optimized method for a single courtyard focused on a shading system that aimed to solve the heat problem and achieve a healthy built environment and sustainability using passive design. By the way, this preserved the Lingnan architectural culture.

By comparing the initial and optimized results in terms of the design of a single courtyard in Lingnan, the heat problem was solved. The light environment was still acceptable after optimization. The sunshade optimization design improved the healthy built environment. Other scholars have carried out similar work at different levels, which provided evidence to prove various aspects of these findings. Huo et al. conducted research using a field test study and proved that the external shading system could effectively decrease the indoor temperature during a hot summer [68]. Lim et al. proved the efficiency of the shading system in reducing the cooling energy consumption in residential buildings [69]. Manzan et al. described the relationship between energy and daylighting caused by shade optimization [70].

However, for a healthy built environment and sustainable building design, interactive research is not enough, as was mentioned in the latest research by Tonne et al. in 2021 [71]. In 2020, Phelan et al. also emphasized that building sustainability, in terms of the building occupants' health, has not received much attention [72]. This research into residential buildings in the Lingnan area adopted an innovative and practical way to study the healthy built environment with sustainable passive design.

\subsection{Contributions}

Therefore, this research contributed in five ways. Firstly, it carried out a literature review of the developing situation and the relationship between the sustainability and healthy built environment concepts. They have been developed over at least 40 years but show an integrated developing trend at present. Under the effects of COVID-19, the healthy built environment is more important than before.

The second way was building a clear research workflow to clarify how to achieve a healthy built environment in a sustainable way using passive design. The single courtyard (facing west) in the Yuedao Residential Community was used as a case study to solve the practical problems while complying with the requirements of healthy building standards. The methods of building performance simulation and on-site measurement were used to get the initial and optimized results. This research process is applicable to other projects.

Third, this research used a wealth of research tools for the simulation of building performance and on-site measurement methods. Kvalue, Ecotect, Cadna/A and Grasshopper software programs were used to analyze thermal, light, and acoustic environments. The BX portable weather station, TES-1341 anemometers, JTR04 black-bulb thermometers, TES-1339R illuminometer, and GM1356 noise meter were used to collect different parameters data. The research methods were used in a complementary way for comprehensive outcomes according to the related standards and references. These provided abundant research details. 
Fourth, the results of the optimization building design not only solved the local problems to varying degrees, but also highlighted the architectural culture in the Lingnan area. The sunshades in the optimization building design focused on the entrance to the west-facing single courtyard, and they provided overall contributions of at least $50 \%$ to the optimization of the Yuedao Residential Community. This research can be used in practical situations, especially in China, according to the local standards.

Fifth, this research filled the gap in the interactive research into the healthy built environment with sustainable passive design. Although few researchers have focused on this to date, the healthy built environment is much more important than before. It is the current trend and a research hotspot in both academic and practical aspects. In the current research, achieving this by sustainable building design according to passive building principles decreased energy use and offered a healthy environment at the same time. This clearly contributes to filling the research gap.

\subsection{Limitations}

A few limitations exist that need to be improved in future research. The first limitation of this research is the difficulty of data collection posed by the on-site measurement conditions. The on-site measurement of the thermal environment did not provide all the data for the ten rooms, although nine rooms were enough, according to GB/T 50785 . Regarding the light environment, because the illumination environment is closely related to the selection of lamps, a sampling inspection of ten rooms was carried out. For the acoustic environment, the on-site measurement started at 6:00 p.m. and was mainly focused on the time when users stayed at home.

Second, the optimization building design was only analyzed with the building performance simulation method. On-site measurement was not carried out because of the lack of an actual optimized single courtyard. This can be carried out if there are appropriate conditions in the future.

The third limitation is that the paper focused on researching the relationship between a healthy built environment and sustainable passive design, so the exact optimization of building design by sunshades was not described in detail. In fact, there are many types of shading systems and other solutions; therefore, these can be researched in future.

The fourth limitation is that this research focused solely on thermal, light, and acoustic environments, according to the related standards. In fact, a healthy built environment must not only pay attention to these three aspects but should also consider the air impacts, Life Cycle Assessment (LAC), GHG emission and so on. These will be researched in the next step $[73,74]$.

\section{Conclusions}

This paper researched how a healthy built environment can be achieved by sustainable passive design. Based on the relevant healthy building standards, the paper summarized the requirements of thermal, light, and acoustic environments. The residential buildings in the Lingnan area were taken as examples of building performance simulation and on-site measurement. After the initial results, the optimized results were analyzed, focusing on solving the existing problems by adding sunshades according to the passive design principle. The main conclusions are as follows:

1. With the focus on the healthy environment and sustainable development over the last 40 years, interactive research, especially into the healthy built environment, is increasingly important at present.

2. This research established a useful workflow for research into the achievement of a healthy built environment using sustainable building design according to the passive building design principle.

3. In this paper, building performance simulation and on-site measurement methods were analyzed with abundant research tools. These tools can be used for more research. 
4. The initial results showed that the temperature of the walls and roof was lower than the $t_{e} \max$. However, the thermal level of the single courtyard was level III. The indoor heat problem remains to be solved, even though the light and acoustic environments met the relevant standards.

5. After optimization, the sunshades offered a better indoor thermal environment. Additionally, the light environment was still good, according to the standards. The optimization design preserved the Lingnan architectural culture.

6. The practical problems were solved to varying degrees. The study made a contribution of at least a $50 \%$ to optimizing the entire Yuedao Residential Community as the buildings that we studied in the single courtyard reflected the whole community except for their orientation.

7. Our study also filled a gap in the interactive research into a healthy built environment with sustainable passive design. This will require more research in the future.

Author Contributions: All authors contributed to the development of the research and the elaboration of this article. Specifically, conceptualization, B.L., X.L. and W.G.; methodology, B.L., X.L. and Y.Z.; software, B.L. and W.G.; validation, W.G., X.L. and Y.Z.; investigation, B.L. and X.L.; data curation, B.L. and W.G.; writing-original draft preparation, B.L., X.L. and W.G.; writing-review and editing, B.L., W.G. and X.L.; supervision, P.J.R. and M.A.S.; funding acquisition, W.G. and X.L. All authors have read and agreed to the published version of the manuscript.

Funding: This research is funded by the National Key R\&D Program of China (Grant No. 2017YFC0702505); Science and Technology Program of Guangzhou, China (Grant No. 202102020302); State Key Laboratory of Subtropical Building Science, South China University of Technology (Grant No. 2021ZB16); the Key R\&D and Achievement Transformation Program of Qinghai Province (Grant No. 2020-SF-137); National Key R\&D Program of China (Grant No. 2020YFE0200300); General Program of the National Natural Science Foundation of China (Grant No. 51938006); Transverse Scientific Research Projects of South China University of Technology (Grant No. x2jzD8197240 and Grant No. x2jzD8205910).

Institutional Review Board Statement: Not applicable.

Informed Consent Statement: Informed consent was obtained from all subjects involved in the study.

Data Availability Statement: The data supporting the findings of this research is available within the article.

Acknowledgments: This research was supported by Architectural Design \& Research Institute Co., Ltd., South China University of Technology. The authors thank all research team members for their contributions.

Conflicts of Interest: The authors declare no conflict of interest.

\section{References}

1. He, B.-J.; Wang, J.; Liu, H.; Ulpiani, G. Localized synergies between heat waves and urban heat islands: Implications on human thermal comfort and urban heat management. Environ. Res. 2021, 193, 110584. [CrossRef] [PubMed]

2. He, B.-J. Towards the next generation of green building for urban heat island mitigation: Zero uhi impact building. Sustain. Cities Soc. 2019, 50, 101647. [CrossRef]

3. Total Energy Consumption. Available online: https://yearbook.enerdata.net/total-energy/world-consumption-statistics.html (accessed on 2 June 2021).

4. Global Energy Review 2021. Available online: https://www.iea.org/reports/global-energy-review-2021?mode=overview (accessed on 2 June 2021).

5. San-Antonio-Gonzalez, A.; Merino, M.; Villoria-Saez, P.; Porras-Amores, C. Evaluation of energy efficiency in existing buildings using CFD simulations of different envelope rehabilitation techniques. In Proceedings of the 4th International Congress on Energy and Environment Engineering and Management, Merida, Spain, 25 May 2011.

6. Zarrabi, M.; Yazdanfar, S.-A.; Hosseini, S.-B. COVID-19 and healthy home preferences: The case of apartment residents in Tehran. J. Build. Eng. 2021, 35, 102021. [CrossRef]

7. D'Amico, A.; Pini, A.; Zazzini, S.; D’Alessandro, D.; Leuzzi, G.; Currà, E. Modelling VOC emissions from building materials for healthy building design. Sustainability 2021, 13, 184. [CrossRef]

8. Sharifi, A.; Yamagata, Y. Roof ponds as passive heating and cooling systems: A systematic review. Appl. Energy 2015, 160, 336-357. [CrossRef] 
9. Uehara, T.; Sakurai, R. Have sustainable development goal depictions functioned as a nudge for the younger generation before and during the covid-19 outbreak? Sustainability 2021, 13, 1672. [CrossRef]

10. Sharifi, A.; Dawodu, A.; Cheshmehzangi, A. Limitations in assessment methodologies of neighborhood sustainability assessment tools: A literature review. Sustain. Cities Soc. 2021, 67, 102739. [CrossRef]

11. Roostaie, S.; Nawari, N.; Kibert, C.J. Sustainability and resilience: A review of definitions, relationships, and their integration into a combined building assessment framework. Build. Environ. 2019, 154, 132-144. [CrossRef]

12. Kibert, C.J. Establishing principle and a model for sustainable construction. In Proceedings of the First International Conference of CIB Task Group 16 on Sustainable Construction, Tampa, FL, USA, 6-9 November 1994.

13. Porras-Amores, C.; Vinas-Arrebola, C.; Rodriguez-Sanchez, A.; Villoria-Saez, P. Assessing the potential use of strategies independent from the architectural design to achieve efficient ventilation: A Spanish case study. Build. Serv. Eng. 2014, 66, 40. [CrossRef]

14. Schnoor, J. Examining the world summit on sustainable development. Environ. Sci. Technol. 2002, 36, 429A-430A. [CrossRef] [PubMed]

15. ISO 15392:2019. Available online: https://www.iso.org/obp/ui/\#!iso:std:69947:en (accessed on 11 April 2021).

16. UN-Habitat Covid-19 Policy and Programme Framework. Available online: https://unhabitat.org/sites/default/files/2020/04/ Covid19_policy_and_programmatic_framework_eng-02.pdf (accessed on 11 April 2021).

17. Wilkinson, P.; Smith, K.R.; Davies, M.; Adair, H.; Armstrong, B.G.; Barrett, M.; Bruce, N.; Haines, A.; Hamilton, I.; Oreszczyn, T.; et al. Public health benefits of strategies to reduce greenhouse-gas emissions: Household energy. Lancet 2009, 374, 1917-1929. [CrossRef]

18. Maiolo, M.; Pirouz, B.; Bruno, R.; Palermo, S.; Arcuri, N.; Piro, P. The role of the extensive green roofs on decreasing building energy consumption in the mediterranean climate. Sustainability 2020, 12, 359. [CrossRef]

19. Gilani, H.A.; Hoseinzadeh, S.; Karimi, H.; Karimi, A.; Hassanzadeh, A.; Garcia, D.A. Performance analysis of integrated solar heat pump VRF system for the low energy building in Mediterranean Island. Renew. Energy 2021, 174, 1006-1019. [CrossRef]

20. Janda, K.B. Buildings don't use energy: People do. Archit. Sci. Rev. 2011, 54, 15-22. [CrossRef]

21. Liu, Z.; Wu, D.; He, B.-J.; Wang, Q.; Yu, H.; Ma, W.; Jin, G. Evaluating potentials of passive solar heating renovation for the energy poverty alleviation of Plateau areas in developing countries: A case study in Rural Qinghai-Tibet Plateau, China. Sol. Energy 2019, 187, 95-107. [CrossRef]

22. Zhong, Z.; Ding, J.; Meng, J. Development of focused schemes of UIA conferences. Architect 2018, 1, $105-109$.

23. Takano, T. Healthy Cities and Urban Policy Research; Spon Press: London, UK, 2003.

24. International Society of Indoor Air Quality and Climate. Available online: https://isiaq.org/ (accessed on 11 April 2021).

25. BRE Global. BREEAM International New Construction; BRE Global: Watford, UK, 2016.

26. Suzer, O. Analyzing the compliance and correlation of LEED and BREEAM by conducting a criteria-based comparative analysis and evaluating dual-certified projects. Build. Environ. 2019, 147, 158-170. [CrossRef]

27. Design Community. A chronicle of healthy residential district development in China. Des. Community. 2016, 6, 8-9.

28. Development of Small Cities \& Towns. Healthy building, a starting point-The technical essentials for construction of healthy housing (2004) press conference \& the 1st forum of theory and practice on healthy housing. Dev. Small Cities Towns 2004, 5, 2-3.

29. Barton, H.; Grant, M. A health map for the local human habitat. J. R. Soc. Promot. Health 2006, 126, 252-253. [CrossRef] [PubMed]

30. Tao, Y.X.; Zhu, Y.; Passe, U. Modeling and data infrastructure for human-centric design and operation of sustainable, healthy buildings through a case study. Build. Environ. 2020, 170, 106518. [CrossRef]

31. Mao, P.; Qi, J.; Tan, Y.; Li, J. An examination of factors affecting healthy building: An empirical study in East China. J. Clean. Prod. 2017, 162, 1266-1274. [CrossRef]

32. Givoni, B. Conservation and the use of integrated-passive energy systems in architecture. Energy Build. 1981, 3, 213-227. [CrossRef]

33. Su, B. The impact of passive design factors on house energy efficiency. Archit. Sci. Rev. 2011, 54, 270-276. [CrossRef]

34. Amirifard, F.; Sharif, S.A.; Nasiri, F. Application of passive measures for energy conservation in buildings-A review. Adv. Build. Energy Res. 2019, 13, 282-315. [CrossRef]

35. Wang, N.; Phelan, P.E.; Gonzalez, J.; Harris, C.; Henze, G.P.; Hutchinson, R.; Langevin, J.; Lazarus, M.A.; Nelson, B.; Pyke, C.; et al. Ten questions concerning future buildings beyond zero energy and carbon neutrality. Build. Environ. 2017, 119, 169-182. [CrossRef]

36. Wang, N.; Phelan, P.E.; Harris, C.; Langevin, J.; Nelson, B.; Sawyer, K. Past visions, current trends, and future context: A review of building energy, carbon, and sustainability. Renew. Sustain. Energy Rev. 2018, 82, 976-993. [CrossRef]

37. The, L. A world of 7 billion people. Lancet 2011, 378, 1527.

38. International Energy Outlook 2019. Available online: https://www.eia.gov/outlooks/ieo/pdf/ieo2019.pdf (accessed on 11 April 2021).

39. Ministry of Housing and Urban-Rural Development of the People's Republic of China (MOHURD). Code for Thermal Design of Civil Building; China Architecture \& Building Press: Beijing, China, 2016.

40. Chen, G.; He, M.; Li, N.; He, H.; Cai, Y.; Zheng, S. A method for selecting the typical days with full urban heat island development in hot and humid area, case study in Guangzhou, China. Sustainability 2021, 13, 320. [CrossRef]

41. MOHURD. Standard of Climatic Regionalization for Architecture; China Planning Press: Beijing, China, 1993.

42. Guo, W.; Li, B.; Dou, J.; Zhang, Z. Research on healthy wind environments of settlements based on epidemic control: A case study of the Lingnan Yuedao settlement. South Archit. 2020, 198, 114-121. 
43. Li, B.; Guo, W.; Schnabel, M.A.; Zhang, Z. Virtual simulation of new residential buildings in Lingnan using vernacular wisdom. In Anthropologic: Architecture and Fabrication in the Cognitive Age. In Proceedings of the 38th eCAADe Conference, Berlin, Germany, 16-18 September 2020; Volume 1, pp. 269-278.

44. Chinese Academy of Building Research. Assessment Standard for Healthy Building; China Architecture \& Building Press: Beijing, China, 2016.

45. Tang, H.; Ding, J.; Li, C.; Li, J. A field study on indoor environment quality of Chinese inpatient buildings in a hot and humid region. Build. Environ. 2019, 151, 156-167. [CrossRef] [PubMed]

46. MOHURD. Evaluation Standard for Indoor Thermal Environment in Civil Buildings; China Architecture \& Building Press: Beijing, China, 2012.

47. Bensafi, M.; Ameur, H.; Kaid, N.; Hoseinzadeh, S.; Memon, S.; Garcia, D.A. Thermophysics analysis of office buildings with a temperature-Humidity coupling strategy under hot-arid climatic conditions. Int. J. Thermophys. 2021, 42, 118. [CrossRef]

48. Li, B.; Guo, W.; Liu, X.; Zhang, Y.; Peter, R. Numerical simulation and field survey on indoor thermal comfort for healthy building: A case study on Lingnan residential building. In Proceedings of the 17th Healthy Buildings Conference, Oslo, Norway, 21-23 June 2021.

49. MOHURD. Standard for Urban Residential Area Planning and Design; China Architecture \& Building Press: Beijing, China, 2018.

50. MOHURD. Standard for Daylighting Design of Buildings; China Architecture \& Building Press: Beijing, China, 2013.

51. Ministry of Environmental Protection of the People's Republic of China. Environmental Quality Standard for Noise; China Environmental Press: Beijing, China, 2008.

52. De Wilde, P. Building Performance Analysis; Wiley: Hoboken, NJ, USA, 2018.

53. MOHURD. Standard for Green Performance Calculation of Civil Buildings; China Architecture \& Building Press: Beijing, China, 2018.

54. Zhang, Y.; Meng, Q.; Li, B. Optimisation design strategy of rural building forms for a healthy microclimate environment. In Proceedings of the 26th CAADRIA Conference, Hong Kong, China, 29 March-1 April 2021.

55. Huang, X.; Zhu, S. Optimization of daylighting pattern of museum sculpture exhibition hall. Sustainability 2021, 13, 1918. [CrossRef]

56. Amani, N. Building energy conservation in atrium spaces based on ecotect simulation software in hot summer and cold winter zone in Iran. Int. J. Energy Sect. Manag. 2018, 12, 298-313. [CrossRef]

57. Gerolymatou, G.; Rémy, N.; Vogiatzis, K.; Zafiropoulou, V. Assessing health effects and soundscape analysis as new mitigation actions concerning the aircraft noise impact in small- and middle-size urban areas in Greece. Environments 2019, 6, 4. [CrossRef]

58. Zhang, L.; Zhang, M.; Li, Z.; Xiao, X.; Sun, N.; Qu, D. Application of Cadna/A software in prediction and assessment of railway noise. Tech. Acoust. 2010, 29, 202-205.

59. Li, B.; Guo, W.; Dou, J.; Liu, X.; Zhang, Y. Research on the Diagnosis and Treatment of Thermal Environment from the Perspective of Healthy Building. Industrial Construction. Available online: https://www.researchgate.net/publication/352363116_ RESEARCH_ON_THE_DIAGNOSIS_AND_TREATMENT_OF_THERMAL_ENVIRONMENT_FROM_THE_PERSPECTIVE_ OF_HEALTHY_BUILDING (accessed on 11 June 2021).

60. Guo, W.; Li, B.; Zhang, Y.; Liu, G. Research on revitalization of nanping village on gaidong cultural route. Landsc. Archit. 2020, $27,118-122$.

61. MOHURD. Standard of Test Methods for Thermal Environment of Building; China Architecture \& Building Press: Beijing, China, 2014.

62. MOHURD. Standard for Lighting Design of Buildings; China Architecture \& Building Press: Beijing, China, 2013.

63. General Administration of Quality Supervision, Inspection and Quarantine of the People's Republic of China. Measurement Methods for Lighting; Standards Press of China: Beijing, China, 2008.

64. Sassi, P. A natural ventilation alternative to the passivhaus standard for a mild maritime climate. Buildings 2013, 3, 61-78. [CrossRef]

65. Liu, S.; Kwok, Y.T.; Lau, K.K.-L.; Ouyang, W.; Ng, E. Effectiveness of passive design strategies in responding to future climate change for residential buildings in hot and humid Hong Kong. Energy Build. 2020, 228, 110469. [CrossRef]

66. Charde, M.; Gupta, R. Effect of energy efficient building elements on summer cooling of buildings. Energy Build. 2013, 67, 616-623. [CrossRef]

67. Lucarelli, C.D.C.; Carlo, J.C. Parametric modeling simulation for an origami shaped canopy. Front. Archit. Res. 2020, 9, 67-81. [CrossRef]

68. Huo, H.; Xu, W.; Li, A.; Cui, G.; Wu, Y.; Liu, C. Field comparison test study of external shading effect on thermal-optical performance of ultralow-energy buildings in cold regions of China. Build. Environ. 2020, 180, 106926. [CrossRef]

69. Lim, T.; Yim, W.S.; Kim, D.D. Evaluation of daylight and cooling performance of shading devices in residential buildings in South Korea. Energies 2020, 13, 4749. [CrossRef]

70. Manzan, M.; Clarich, A. FAST energy and daylight optimization of an office with fixed and movable shading devices. Build. Environ. 2017, 113, 175-184. [CrossRef]

71. Tonne, C.; Adair, L.; Adlakha, D.; Anguelovski, I.; Belesova, K.; Berger, M.; Brelsford, C.; Dadvand, P.; Dimitrova, A.; Giles-Corti, B.; et al. Defining pathways to healthy sustainable urban development. Environ. Int. 2021, 146, 106236. [CrossRef]

72. Phelan, P.; Wang, N.; Hu, M.; Roberts, J.D. Editorial: Sustainable, healthy buildings \& communities. Build. Environ. 2020, $174,106806$. 
73. Hoseinzadeh, S.; Zakeri, M.; Shirkhani, A.; Chamkha, A. Analysis of energy consumption improvements of a Zero-energy building in a humid mountainous area. J. Renew. Sustain. Energy 2019, 11, 015103. [CrossRef]

74. Huang, W.; Liu, X.; Zhang, S.; Zheng, Y.; Ding, Q.; Tong, B. Performance-Guided Design of Permeable Asphalt Concrete with Modified Asphalt Binder Using Crumb Rubber and SBS Modifier for Sponge Cities. Materials 2021, 14, 1266. [CrossRef] 